\title{
School Start Times and Teenage Driver Motor Vehicle Crashes
}




\section{Disclaimer}

This publication is distributed by the U.S. Department of Transportation, National Highway Traffic Safety Administration, in the interest of information exchange. The opinions, findings, and conclusions expressed in this publication are those of the authors and not necessarily those of the Department of Transportation or the National Highway Traffic Safety Administration. The United States Government assumes no liability for its content or use thereof. If trade or manufacturers' names or products are mentioned, it is because they are considered essential to the object of the publication and should not be construed as an endorsement. The United States Government does not endorse products or manufacturers. 


\begin{tabular}{|c|c|c|c|c|}
\hline $\begin{array}{l}\text { 1. Report No. } \\
\text { DOT HS } 812221\end{array}$ & \multicolumn{2}{|c|}{ 2. Government Accession No. } & \multicolumn{2}{|c|}{ 3. Recipient’s Catalog No. } \\
\hline \multicolumn{3}{|c|}{ School Start Times and Teenage Driver Motor Vehicle Crashes } & \multicolumn{2}{|l|}{ December 2015} \\
\hline \multirow{2}{*}{\multicolumn{3}{|c|}{$\begin{array}{l}\text { 7. Author(s) } \\
\text { Robert D. Foss, Ph.D., Richard L. Smith, Ph.D., } \\
\text { Funan Shi, Natalie P. O’Brien, M.S. }\end{array}$}} & \multicolumn{2}{|c|}{ 6. Performing Organization Code } \\
\hline & & & \multicolumn{2}{|c|}{ 8. Performing Organization Report No. } \\
\hline \multirow{2}{*}{\multicolumn{3}{|c|}{$\begin{array}{l}\text { 9. Performing Organization Name and Address } \\
\text { Highway Safety Research Center \& } \\
\text { Department of Statistics and Operations Research } \\
\text { University of North Carolina at Chapel Hill } \\
\text { Chapel Hill, NC } 27599\end{array}$}} & \multicolumn{2}{|c|}{ 10. Work Unit No. (TRAIS) } \\
\hline & & & \multicolumn{2}{|c|}{ 11. Contract or Grant No. } \\
\hline \multirow{2}{*}{\multicolumn{3}{|c|}{ 12. Sponsoring Agency Name and Address }} & \multicolumn{2}{|c|}{$\begin{array}{l}\text { 13. Type of Report and Period Covered } \\
\text { Research Report }\end{array}$} \\
\hline & & & \multicolumn{2}{|c|}{ 14. Sponsoring Agency Code } \\
\hline \multicolumn{5}{|c|}{ 15. Supplementary Notes: Contracting Officer’s Technical Representative - Randolph Atkins, Ph.D. } \\
\hline \multicolumn{5}{|l|}{ 16. Abstract } \\
\hline \multicolumn{5}{|c|}{$\begin{array}{l}\text { There is substantial evidence that lack of sleep is a significant factor in motor vehicle crashes experienced by } \\
\text { teenage drivers. This report examines the hypothesis that a later high school start time may reduce crash rates by } \\
\text { reducing the interference of school start time with the sleep needs of adolescents. We collected data from two } \\
\text { jurisdictions, Forsyth County, North Carolina, and Fayette County, Kentucky, that changed to substantially later } \\
\text { high school start times. We examined whether these changes were accompanied by a drop in crash rates among } \\
\text { 16- and } 17 \text {-year-old drivers. Monthly time series were compiled corresponding to the overall rate of crashes on } \\
\text { school days, adjusted for the } 16 \text { - and } 17 \text {-year-old population. An intervention time series analysis was applied to } \\
\text { determine whether the change in school start time was accompanied by a downward shift in the level of the crash } \\
\text { rate series. To control for possible confounding factors, comparable statistics were also compiled, using the same } \\
\text { analyses, for several other counties where there was no change in school start times. For Forsyth County, North } \\
\text { Carolina, there was a decrease in crash rates corresponding to the change in school start time, though the } \\
\text { statistical significance of the effect is only moderate (one-sided p-value = .04). No corresponding effect was } \\
\text { observed for three comparable counties of North Carolina. For Fayette County, Kentucky, there was no evidence } \\
\text { of a statistically significant change in crash rates. Because of anomalous data in the one available comparable } \\
\text { county, we were unable to derive meaningful results for a comparison county in Kentucky. We conclude that } \\
\text { there is mild evidence that the change in school start times in Forsyth County, North Carolina, had a beneficial } \\
\text { effect, but there is no corresponding evidence for Fayette County, Kentucky. }\end{array}$} \\
\hline $\begin{array}{l}\text { 17. Key Words } \\
\text { teenage drivers, young drivers, } \\
\text { fatigue, drowsy driving, high sch }\end{array}$ & $\begin{array}{l}\text { adolescent drivers, } \\
\text { oool start time }\end{array}$ & $\begin{array}{l}\text { 18. Distribution } \\
\text { This document } \\
\text { Technical Inforı }\end{array}$ & $\begin{array}{l}\text { atement } \\
\text { available to the pr } \\
\text { ion Service www. }\end{array}$ & $\begin{array}{l}\text { ic from the National } \\
\text { s.gov. }\end{array}$ \\
\hline $\begin{array}{l}\text { 19. Security Classif. (of report) } \\
\text { Unclassified }\end{array}$ & $\begin{array}{l}\text { 20. Security Class } \\
\text { Unclassified }\end{array}$ & if. (of this page) & $\begin{array}{l}\text { 21. No. of pages } \\
50\end{array}$ & 22. Price \\
\hline
\end{tabular}


This page intentionally left blank 


\section{Table of Contents}

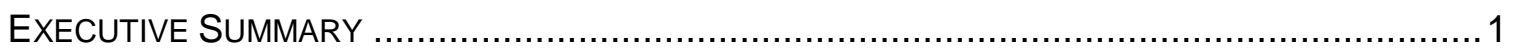

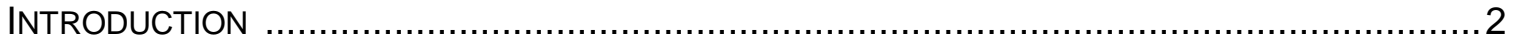

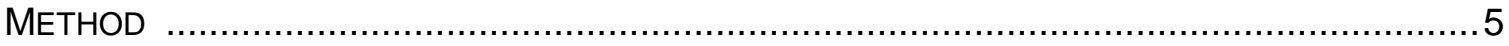

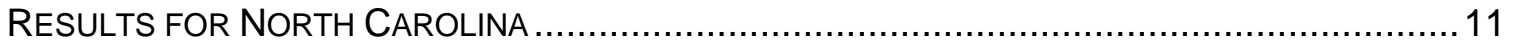

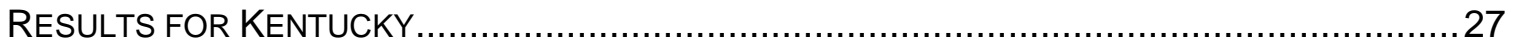

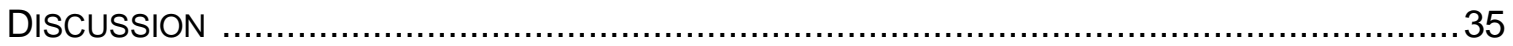

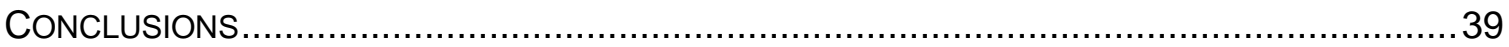

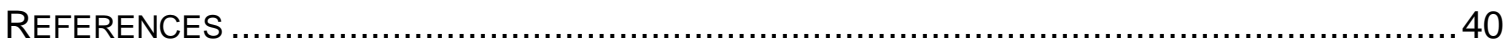

\section{List of Tables}

Table 1. Number of schools, enrollment and daily school start times

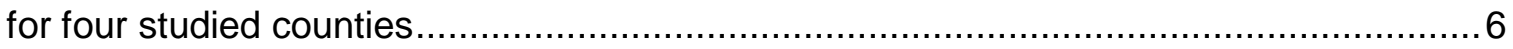

Table 2. Number of 16- and 17-year-olds, in the intervention (Forsyth) and

three North Carolina comparison counties for the years of study .............................. 7

Table 3. Definition of data series time periods ("months") ..................................... 8

Table 4. Results of model (5) for the time series from Forsyth County, NC..................20

Table 5. The $\beta_{1}$ parameter estimates from model (5) fitted to

five different time periods for Forsyth County........................................................ 21

Table 6. Results of model (5) for the time series from Guilford County .......................21

Table 7. The $\beta_{1}$ parameter estimates from model (5) fitted to

five different time periods for Guilford County ................................................... 22

Table 8. Results of model (5) for the time series from Mecklenburg County .................22

Table 9. The $\beta_{1}$ parameter estimates from model (5) fitted to

five different time periods for Mecklenburg County ................................................ 23

Table 10. Results of model (5) for the time series from Wake County ..........................23

Table 11. The $\beta_{1}$ parameter estimates from model (5) fitted to

five different time periods for Wake County

Table 12. Summary table of the $\beta_{1}$ parameter from model (5) fitted to

five different time periods for Forsyth and 3 comparison Counties.............................24

Table 13. Hour by hour analyses for Forsyth County ......................................... 26

Table 14. Populations of 16- and 17-year-olds, in Fayette (intervention)

and Jefferson (comparison) Counties, Kentucky for the years of study....

Table 15. Summary of separate time period analyses, model (5) results

for Fayette County KY. 


\section{List of Figures}

Figure 1. Adjusted monthly crash rates, 6 am to $6 \mathrm{pm}$, in four NC counties..................13

Figure 2a. Adjusted monthly crash rates, 6 am - 9 am, in four NC counties.................. 14

Figure 2b. Adjusted monthly crash rates, 9 am - Noon, in four NC counties ................. 15

Figure 2c. Adjusted monthly crash rates, Noon - 3 pm, in four NC counties ................. 16

Figure $2 \mathrm{~d}$. Adjusted monthly crash rates, $3 \mathrm{pm}-6 \mathrm{pm}$, in four NC counties.................. 17

Figure 2e. Adjusted monthly crash rates, 6 pm - 6 am, in four NC counties................. 18

Figure 3. Adjusted monthly crash rates, by single hour, Forsyth County, NC............... 25

Figure 4a. Adjusted monthly crash rates, three time periods, Fayette County, KY.........29

Figure 4b. Adjusted monthly crash rates, four time periods, Fayette County, KY.......... 31

Figure 5. Adjusted monthly daytime and nighttime crash rates, Jefferson County, KY .. 34 


\section{EXECUTIVE SUMMARY}

There is substantial evidence that lack of sleep is a significant factor in motor vehicle crashes experienced by teenage drivers. This paper examines the hypothesis that a later high school start time may reduce crash rates by reducing the interference of school start time with the sleep needs of adolescents. We collected data from two jurisdictions - Forsyth County, North Carolina and Fayette County, Kentucky - that changed to a substantially later high school start time. We examined whether this change was accompanied by a drop in crash rates among 16- and 17-year-old drivers.

Monthly time series were compiled corresponding to the overall rate of crashes on school days, adjusted for changes in the 16- and 17-year-old population. An intervention time series analysis was applied to determine whether the change in school start time was accompanied by a downward shift in the level of the crash rate series. To control for possible confounding factors, comparable statistics were also compiled, using the same analyses, for several other counties where there was no change in school start times.

For Forsyth County, NC, there was a decrease in crash rates corresponding to the change in school start time, though the statistical significance of the effect is only moderate (one-sided $p$-value $=.04$ ). No corresponding effect was observed for three comparable counties of North Carolina. For Fayette County, KY, there was no evidence of a statistically significant change in crash rates. Because of anomalous data in the one available comparable county, we were unable to derive meaningful results for a comparison county in Kentucky.

We conclude that there is mild evidence that the change in school start times in Forsyth County, NC had a beneficial effect, but there is no corresponding evidence for Fayette County, KY. 


\section{INTRODUCTION}

Driving while sleepy or tired can result in decreased alertness, slowed reaction times, failures to notice emergency situations and, in the extreme, falling asleep. Accurate data on the role of fatigue or drowsiness in crashes are difficult to obtain from existing data bases. However, according to NHTSA's Crashworthiness Data System (CDS), from 2000-2003 approximately 4\% of crashes involved a driver who was either sleepy or had fallen asleep. One of the original studies of drowsy-driving crashes found that individuals younger than 25 years of age accounted for a majority of drowsy driving crashes in North Carolina (Pack et al., 1995). More recent national evidence indicates that drivers under age 21 , who comprise about $6 \%$ of the licensed driving population, account for about $20 \%$ of drowsy driving crashes (NHTSA, 2005). This overinvolvement by young drivers may result, in part, from an interaction between driving experience and hazard perception. One recent study suggests that more experienced drivers are less susceptible to degradation of their hazard perception abilities when they are sleepy than less experienced drivers (Smith et al., 2009).

Developments in understanding human sleep needs during the past decade may provide further explanation for the over-involvement of young drivers in drowsy driving crashes. Circadian rhythms change during adolescence, leading teenagers to fall asleep later than when they were younger (Wolfson \& Carskadon, 1998, 2003). As a consequence of this "sleep phase shift," to obtain sufficient rest adolescents need to be asleep in the early morning hours (e.g., 6 - 7 am) (National Sleep Foundation, 2000). Although developments in a wide range of technologies and in social networking have substantially altered the lives of teenagers during the past decade, the shift in circadian rhythm is a biological phenomenon and not simply a matter of teens choosing to go to bed later (Carskadon et al., 2004). When this unavoidable developmental change occurs in the context of a "24-hour world" that now encourages later bedtimes for nearly everyone, along with school start times that have become progressively earlier, the result has been an increasing number of seriously sleep-deprived adolescents. Yang et al. (2005) reported that whereas 5th \& 6th graders cite television-watching and internet activities (in addition to academic pressures) as responsible for their sleep deprivation, 10th-12th graders cite early school start times along with academic pressures as the primary contributors. High school bell schedules typically begin earlier than those of middle and elementary schools. This often results from efforts to minimize the number 
of buses needed in a school district by sequencing bus runs so that multiple morning runs with the same buses can accommodate all students who need transportation.

As the critical importance of sleep has come to be more fully recognized and teen sleep patterns better understood, some school systems in the U.S. have reversed the decades-long trend toward earlier high school start times. These policy changes are designed to avoid causing serious sleep deficits and the resulting consequences in the teenage population. Moving start times back from 7:30 am or earlier to 8:30 am or later appears to have produced improvements in academic performance and decreases in disruptive behavior (Dexter et al., 2003; Wolfson \& Carskadon, 1998).

A study of a one hour county-wide delay in high school start times in Kentucky found another potential benefit of such policies: a reduction in teenage driver crashes (Danner 2002; Danner \& Phillips, 2008). After the high school start time was changed from 8 am to 9 am in Fayette County (Lexington metropolitan area), the crash rate among licensed $17 \& 18$-year-old drivers declined $16 \%$ during the two years following the change, compared with the previous two years. During the same time period, crashes throughout the rest of the state increased by $8 \%$ for this age group.

The Kentucky findings suggest that a relatively simple policy change, which can be made at the local level, may potentially produce a dramatic improvement in teen driver safety. A recent cross-sectional study of two large, adjacent counties in southeastern Virginia with high school start times that differ by 80 minutes (7:20 vs 8:40 am) reported a 29\% lower per capita crash rate among 16-18 year-olds in the county with the later start time (Vorona et al., 2010). To date, however, only Danner \& Phillips (2008) have attempted to examine the effect of an actual change in school start times on young driver crashes. Replication of this finding is desirable before local officials embrace this policy in pursuit of teenage driver safety. A replication would, ideally, avoid some limitations of the Kentucky study. Moreover, if this effect can be replicated elsewhere, it is important to document its duration. It is possible, perhaps even likely, that students adapt to a new schedule and begin to go to bed even later, eroding or completely removing the beneficial effect of a shift in start times. The use of a simple before-after study design in the Kentucky study precluded a more detailed look at whether the decrease in young driver crashes was closely associated with the timing of the policy change. Nor was it possible to determine whether the decreased crash rate endured or had begun to erode by the end of the 2-year follow-up period. 
One particular concern with the analyses reported by Danner \& Phillips is that the studied population was not matched particularly well to the intervention. First, 16 yearolds, who represent a substantial proportion of high school age drivers, were excluded from the analyses. ${ }^{1}$ At the same time, many of the drivers whose crashes were included would not have been affected by the shift in school start times. In any given year, most 18 year-old drivers are no longer in high school, hence would be unaffected by school start time. Some students graduate before turning 18 and most will have done so well before they are 19 years old. A number of others drop out of school before turning 18 . An additional concern with the Kentucky study is that the analysis included crashes during periods when school was not in session (summer, weekends, holidays). Finally, by using all counties in a largely rural state as the comparison for an urban-suburban county, the Kentucky study employed a relatively crude, non-equivalent comparison group.

A more refined analytic approach to this issue would help to more effectively rule out alternative explanations for the apparent beneficial effect on young driver crashes of delaying the high school start time. The present study is an attempt to do this, examining an age group and time periods more directly subject to effects of an altered high school start time in another jurisdiction where the school start time was delayed.

Beginning in August 2003, Forsyth County, North Carolina (2003 population $=317,430$ ) altered the start time by 75 minutes for all public high schools, moving it back from 7:30 am to $8: 45 \mathrm{am}$. The present study was undertaken primarily to determine whether this change resulted in a decrease in crashes among high school age drivers. This study is also an attempt to replicate the Kentucky finding with a study design that focused more tightly on when, and the population in which, the effect would be expected. In addition, we sought to determine whether the effect, if replicated, endures or erodes over time.

Because of the several noted limitations to the Danner \& Phillips (2008) study, we also obtained Kentucky crash data to conduct a conceptual replication, using a more refined analytic approach that focused on 16- and 17-year-old driver crashes during times when school was in session.

\footnotetext{
${ }^{1}$ Although Danner \& Phillips provide no explanation for this exclusion, it may have been to avoid the possible contaminating effect of coincident changes in Kentucky's young driver licensing system. These changes reduced crashes among 16-year-olds by nearly one-third by increasing the mandatory learner period from one month to 6 months duration (Agent et al., 2001).
} 


\section{METHOD}

\section{North Carolina Crash Data}

Data were obtained from the North Carolina Crash Data System for crashes involving drivers ages 16 and 17 who held a North Carolina driver license from January 2000 through June 2007. This data base includes all police-reported crashes occurring on a public roadway and involving either injury or more than $\$ 500$ damage. North Carolina, like Kentucky, is a relatively rural state, with a substantial proportion of the population living in rural areas. This results in a great deal of driving on rural roads, where crash risks differ substantially from urban/suburban driving. Accordingly, we chose not to use the entire state for comparison to limit the range of factors that contribute to young novice driver crashes in the intervention and comparison counties. Analyses were limited to crashes that occurred in Forsyth County and the three larger counties in North Carolina (Guilford, Mecklenburg and Wake). These three counties are fairly comparable to Forsyth in terms of urbanization and homogeneity of driving environment. The 2003 population densities in Forsyth, Guilford, Mecklenburg and Wake Counties were 747, 648,1322 , and 755 persons per square mile, respectively. The population density for North Carolina as a whole was 165 persons per square mile.

The starting date of January 2000 was selected because a new crash reporting form was adopted at that time, creating a number of inconsistencies with data recorded using the previous form. Moreover, the young driver licensing system was altered to create a multi-stage graduated driver licensing system in December 1997. This produced some dramatic changes in the nature of the young driver cohort and in crash rates among high school age drivers (cf., Foss, Feaganes \& Rodgman, 2001). The young driver licensing system had returned to a state of equilibrium by July 1999, but the crash rate has remained substantially lower among high school age drivers. Use of three comparison counties for the present analyses should control for any possible unknown, longer term after-effects of this change in the licensing process. 


\section{School Data}

Table 1 summarizes information about the schools in the counties studied. Two of the comparison counties - Guilford and Mecklenburg - had uniform start times for all public high schools. Start times in the Wake County schools were not uniform, varying from 7:25 am to 8:05 am, but most started at 7:25 am; the mean start time was 7:36 am in 2003. These start times have remained largely constant since 2000 although they occasionally shifted by a few minutes from year to year, especially in Wake County. In Forsyth County the uniform start time for all public high schools was 7:30 am until August 2003, when it was shifted to 8:45 am There are private high schools in all four counties, whose start times often differ from those of public schools. Information about start times was not available for most private schools. Many of these schools are quite small, with fewer than 50 students.

Table 1. Number of schools, enrollment and daily school start times for four studied counties.

\begin{tabular}{lcccc}
\hline County & N & $\begin{array}{c}\text { Fall 2003 } \\
\text { Enrollment }\end{array}$ & Original start time & New start time \\
\hline \hline Forsyth & 8 & 12,500 & $7: 30 \mathrm{am}$ & $8: 45 \mathrm{am}$ \\
Guilford & 14 & 18,150 & $8: 40 \mathrm{am}$ & Same \\
Mecklenburg & 15 & 27,950 & $7: 15 \mathrm{am}$ & Same \\
Wake & 16 & 28,150 & $7: 36 \mathrm{am}^{\star}$ & Same \\
\hline
\end{tabular}

* Start times were not uniform across Wake County. 7:36 am was the mean start time in 2003.

Details about the school calendars of all four school systems were compiled from official school records and by speaking with school system officials in each county. This information included the days that school was scheduled to be in session, days when school was canceled due to inclement weather and make-up days when school was actually in session though not originally scheduled as a class day. In combination with the crash data, this information was used to calculate crash rates per school day in session. 


\section{Population Data}

The population grew substantially in all four NC counties during the period under study with total population increases between 2000 and 2007 ranging from $8.7 \%$ to $30.9 \%$. The number of 16- and 17-year-olds grew at an even faster rate in all counties (see Table 2). To account for the effect of population increase on crashes, annual census estimates of the number of 16- and 17-year-old residents of each county were obtained from the office of the North Carolina State Demographer. These were used to adjust for population changes.

Table 2. Number of 16- and 17-year-olds, in the intervention (Forsyth) and three North Carolina comparison counties for the years of study.

\begin{tabular}{|c|c|c|c|c|}
\hline \multirow[b]{2}{*}{ Year } & \multicolumn{4}{|c|}{ County } \\
\hline & Forsyth & Guilford & Mecklenburg & Wake \\
\hline 2000 & 7514 & 10141 & 17156 & 15440 \\
\hline 2001 & 7716 & 10349 & 18084 & 16745 \\
\hline 2002 & 8060 & 10943 & 19230 & 17964 \\
\hline 2003 & 8368 & 11379 & 20076 & 18808 \\
\hline 2004 & 8621 & 11477 & 20811 & 19651 \\
\hline 2005 & 8946 & 11864 & 21530 & 20847 \\
\hline 2006 & 9688 & 12580 & 22741 & 22461 \\
\hline 2007 & 10311 & 13041 & 24117 & 23906 \\
\hline
\end{tabular}

\section{Construction of Time Series}

We examined monthly crash counts from January 2000 through June $2007 .^{2}$ However, because school was not in session on weekends or during the summer, these days/periods were excluded from the analysis. Rather than using calendar month as the unit of analysis, we redefined "months" to capture as many school-in-session days as possible, while simultaneously excluding the summer recess period. Accordingly, as examined here, each year contained 10 months. Month 1 of each year runs from January 10 through February 9; Month 2 from February 10 through March 9;... Month

\footnotetext{
${ }^{2}$ A new crash reporting system was implemented in January 2000, rendering data for prior years somewhat incomparable. The analysis begins with January, rather than August, 2000 to obtain the maximum number of preintervention months. To maximize the number of data points available for analysis we included the most recent school month for which crash data were complete at the time analysis began.
} 
10 from December 10 through January 9 the following year. Table 3 shows the periods covered by each time unit (month) in the analysis (January 1-9, 2000, are not included in the analysis). As thus defined, the dataset covers a total of 75 months, 10 each in years 2000-2006 and 5 in 2007.

Table 3. Definition of data series time periods ("months").

\begin{tabular}{clclc}
\hline Month & \multicolumn{1}{c}{ Begin date } & \multicolumn{2}{c}{ End date } \\
\hline \hline 1 & January 10 & 2000 & February 9 & 2000 \\
2 & February 10 & 2000 & March 9 & 2000 \\
3 & March 10 & 2000 & April 9 & 2000 \\
4 & April 10 & 2000 & May 9 & 2000 \\
5 & May 10 & 2000 & June 9 & 2000 \\
6 & August 10 & 2000 & September 9 & 2000 \\
7 & September 10 & 2000 & October 9 & 2000 \\
8 & October 10 & 2000 & November 9 & 2000 \\
9 & November 10 & 2000 & December 9 & 2000 \\
10 & December 10 & 2000 & January 9 & 2001 \\
11 & January 10 & 2001 & February 9 & 2001 \\
12 & February 10 & 2001 & March 9 & 2001 \\
13 & March 10 & 2001 & April 9 & 2001 \\
. & $\cdot$ & $\cdot$ & $\cdot$ & $\cdot$ \\
$\cdot$ & $\cdot$ & $\cdot$ & $\cdot$ & $\cdot$ \\
$\cdot$ & $\cdot$ & 2007 & April 9 & 2007 \\
73 & March 10 & 2007 & May 9 & 2007 \\
74 & April 10 & 2007 & June 9 & 2007 \\
75 & May 10 & & & \\
\hline
\end{tabular}

The number of crashes per school-in-session day involving drivers age 16 or 17 was calculated for each month. Using age-specific population estimates for each county, we calculated a population-adjusted series as the number of crashes per school day, per 10,000 16-17-year-old county residents the year of the crash.

The initial time series were constructed by aggregating all hours of the day. However, since the time of the crash is important in some analyses, we also computed time series 
restricted to specific periods of the day ( 6 am to $9 \mathrm{am}, 9 \mathrm{am}$ to noon, noon to $3 \mathrm{pm}, 3$ pm to $6 \mathrm{pm}, 6 \mathrm{pm}$ to $6 \mathrm{am}$ ), and for individual hours ( $6 \mathrm{am}$ to $7 \mathrm{am}, 7 \mathrm{am}$ to $8 \mathrm{am}$, etc.).

\section{Statistical Analysis Methods}

To obtain an initial assessment of a possible change point, we fitted the following regression model to each time series:

$$
x_{t}=\beta_{0}-\beta_{1} t+\beta_{2} I(t>35)+\sum \beta_{2+j}\left(m_{t j}-\bar{m}_{\cdot j}\right)+\varepsilon_{t} .
$$

Here, $\beta_{0}$ is an intercept, $\beta_{1}$ is a linear time trend, $\beta_{2}$ is the size of the change point after time 35 (i.e. month 35 of the data, which corresponds to the month of the school start time change in Forsyth County), and $\beta_{3}, \ldots, \beta_{11}$ are monthly coefficients. The variable $m_{t i j}$ is an indicator: 1 if time point $t$ is in month $j, 0$ otherwise. We define this for $j=1, \ldots$, 9: the value for $j=10$ is by default assumed to be 0 . The variable $\bar{m}_{. j}$ is the mean of $m_{t j}$ over all $t$, and we assume the standard linear regression model that the errors $\varepsilon_{t i j}$ are uncorrelated with mean 0 and common variance. The model (1) is fitted by ordinary least squares regression and the fitted line without monthly mean terms, i.e., $\hat{\beta}_{0}+\hat{\beta}_{1} t+$ $\hat{\beta}_{2} I(t>35)$, is shown in the plots of the time series given below. In this way, we are able to visualize the separate effects of the change point and the overall trend. We do not make any attempt to calculate standard errors for this regression because those are derived through a more detailed ARIMA analysis, which is described next.

The general strategy behind intervention analysis (based on ARIMA time series models) has been described in numerous places. Box and Tiao (1975) first suggested the approach, while Brockwell and Davis (2003) provide a good introductory overview of the methodology.

Given that initial plots of the time series show clear visual evidence of both trend and seasonality, it is natural to start by differencing the series at a lag of one year:

$$
y_{t}=x_{t}-x_{t-10}, \quad t=11, \ldots, 75
$$


Ignoring for the moment the possibility of a change point, we fit a seasonal ARIMA time series model to $y_{t}$ :

$$
\phi(B) \Phi(B)\left(y_{t}-\mu\right)=\theta(B) \Theta(B) \varepsilon_{t} .
$$

Here:

$$
\begin{aligned}
& \phi(B)=1-\sum_{i=1}^{p} \phi_{i} B^{i} \quad \text { is the autoregressive operator of order } p \\
& \Phi(B)=1-\sum_{i=1}^{r} \Phi_{i} B^{i s} \quad \begin{array}{l}
\text { is the seasonal autoregressive operator of order } P \text { and } \\
\text { seasonality } s=10
\end{array} \\
& \theta(B)=1+\sum_{i=1}^{4} \theta_{i} B^{i} \quad \text { is the moving average operator of order } q \\
& \Theta(B)=1+\sum_{i=1}^{\varphi} \Theta_{i} B^{i s} \text { is the seasonal moving average operator of order } Q .
\end{aligned}
$$

Here $B$ is the backshift operator $\left(B^{k} y_{t}=y_{t-k}\right)$ and $\mu$ is the overall mean. If $\mu<0$, then there is an overall decrease in crash rates over the time period of the study, but this conclusion in itself does not imply that the decrease is due to the change in school start times; for that we need a more specific "intervention analysis."

To extend model (3) to the case with an intervention (or change point), we write

$$
\phi(B) \Phi(B)\left(y_{t}-\beta_{0}-\beta_{1} z_{t}\right)=\theta(B) \Theta(B) \varepsilon_{t} .
$$

Thus the constant mean $\mu$ in (3) is replaced by a regression function $\beta_{0}+\beta_{1} z_{t}$, where $z_{t}$ is the following indicator function: $z_{t}=1$ for $t=36,37, \ldots, 45$, otherwise $z_{t}=0$. The rationale for this definition of $z_{t}$ is that model (4) has been derived from (1) by differencing at lag 10: $z_{t}$ is precisely the differenced version of the function $I(t>35)$. However, by including the autoregressive and moving average operators in (4), we allow correctly for time series dependence.

A key step for the application of (3) or (4) is the selection of model orders $p, P, q, Q$. Here, $p$ and $q$ refer to the non-seasonal part of the model - larger values of $p$ and $q$ would indicate a higher degree of autocorrelation over consecutive months within a year, while the values of $P$ and $Q$ relate to autocorrelations at multiples of one year (in this case,10 months) and therefore reflect the seasonal effects in the data. There is no universally agreed upon procedure for selecting these model orders. There are various 
semi-automated methods such as the Akaike Information Criterion (AIC; Akaike 1973), the Bayesian information criterion (BIC; Akaike 1978) or the bias-corrected Akaike Information Criterion (AICC), introduced for time series by Hurvich and Tsai (1989). We have used each of these criteria to help guide the model choice, but without regarding any of them as absolute. We have also tried out various time series models using the test of Ljung and Box (1978). This is a test for autocorrelation among the residuals of a time series model; if the hypothesis of uncorrelated residuals is accepted, then the time series model is taken to be a reasonable fit to the data. All of these methods are described in standard time series texts, such as Brockwell and Davis (2003). In most of the following analyses, we use $p=P=q=0, Q=1$, in which case the model (4) reduces to

$$
y_{t}-\beta_{0}-\beta_{1} z_{t}=\varepsilon_{t}+\Theta_{1} \varepsilon_{t-10} .
$$

In this model, the parameter $\Theta_{1}$ accounts for the autocorrelation at lag 10 , which is a measure of seasonal effect. This has the advantage of being a relatively simple model, which appears to fit most of the time series examined and passes the Ljung-Box test in most cases.

The actual analysis was conducted in the statistical package $R$ ( $R$ Development Core Team, 2010), in particular using the ARIMA function in $R$.

\section{Results fOR NORTH CAROLINA}

\section{Initial identification of changes in crash rates}

The following several figures show plots of the adjusted series for the four North Carolina counties studied. The vertical dashed line is at month 35, i.e., before August 2003, the month in which the later school start time was introduced in Forsyth County. Each plotted data point represents the crash rate per school day in session during the month, per 10,000 16- and 17-year-olds in the county as described above. Thus, for example, if there were 36 crashes on the 18 days that school was in session during a month, the unadjusted crash rate per school day for the month would be $36 / 18=2.00$. If the county had a population of 840016 - and 17-year-olds, the mean populationadjusted monthly crash rate per school day in session would be $(36 / 18) /(8,400 / 10,000)$ $=2.00 / .84=2.38$. 
Figure 1 shows a plot of the adjusted daytime crash series ( 6 am to $6 \mathrm{pm}$ ). It is apparent that there is seasonality in the data, with more crashes during the autumn months and fewer in the springtime. There are also downward trends of varying strengths in all four counties. The overall trend is especially strong in Mecklenburg County.

Prior to conducting a formal time-series analysis, the model described in equation (1) was fitted to each data series, and the resulting trend drawn on the monthly crash plots to take an initial look for a possible change in the level of the series. As is shown in Figure 1, there is a small, but perceptible, downward shift at the time of the school policy change for Forsyth County. However, when the same regression model is fitted, there is also a downward shift for Guilford County, which has to be spurious since there was no change in school policy there. The other two counties, Mecklenburg and Wake, show no evidence of any shift in crash rates.

To examine this in more detail, we repeated the above calculations for five subsets of the day: $6 \mathrm{am}-9 \mathrm{am}, 9 \mathrm{am}-$ noon, noon $-3 \mathrm{pm}, 3 \mathrm{pm}-6 \mathrm{pm}$ and $6 \mathrm{pm}-6 \mathrm{am}$. The results are shown in Figures 2a. to 2e. 
Forsyth

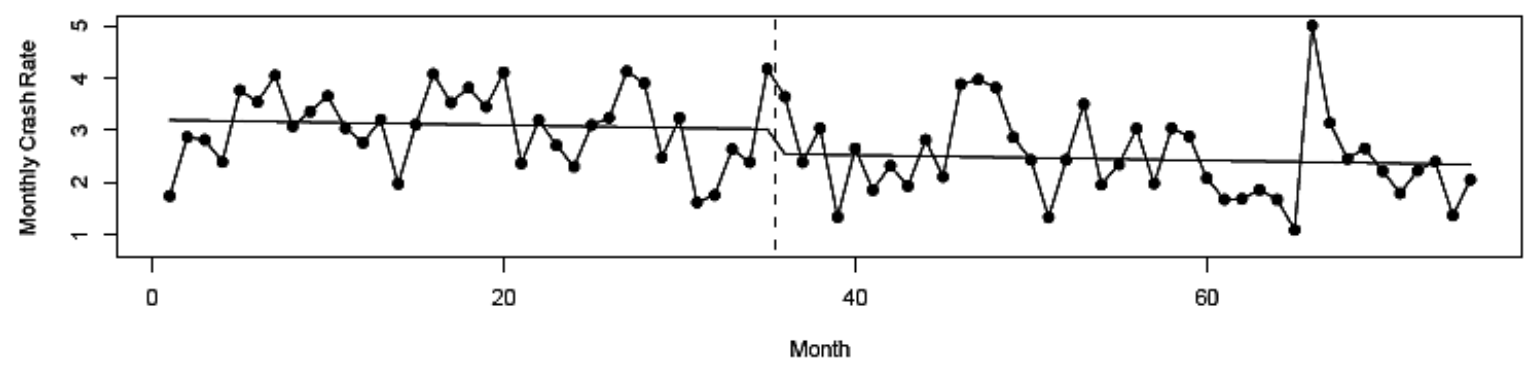

Guilford

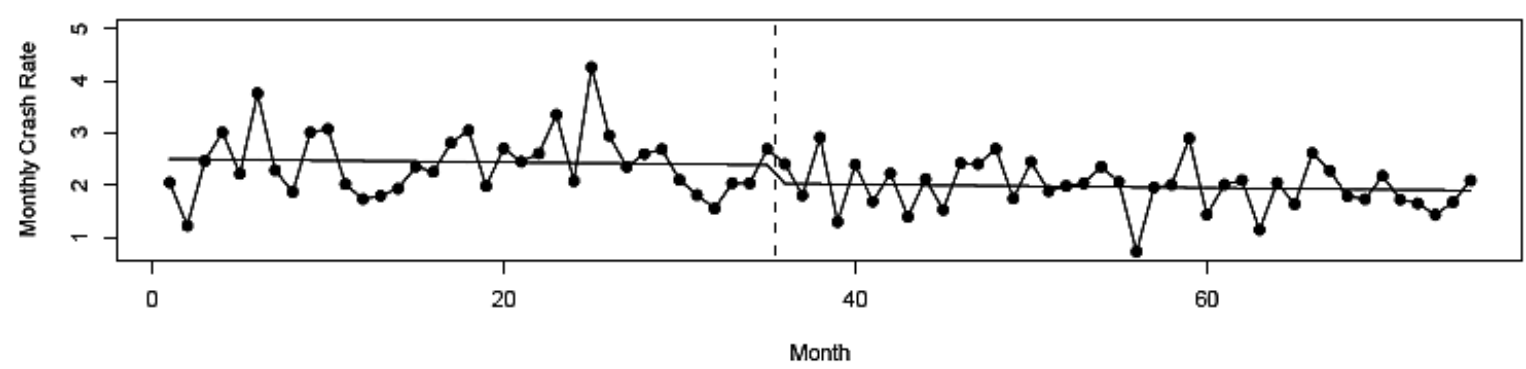

Mecklenburg

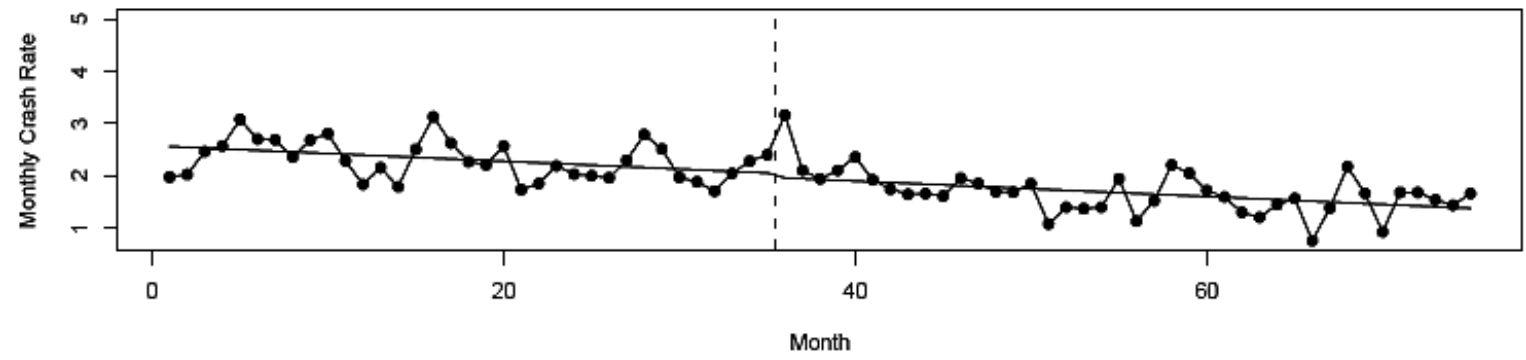

Wake

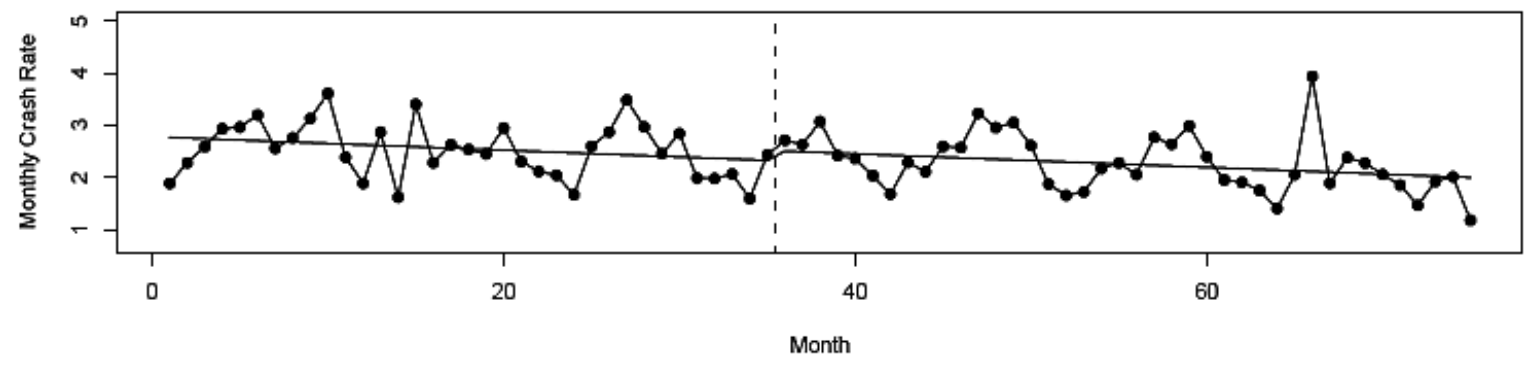

Figure 1. Adjusted monthly crash rates, 6 am to $6 \mathrm{pm}$, in four NC counties. 
Forsyth

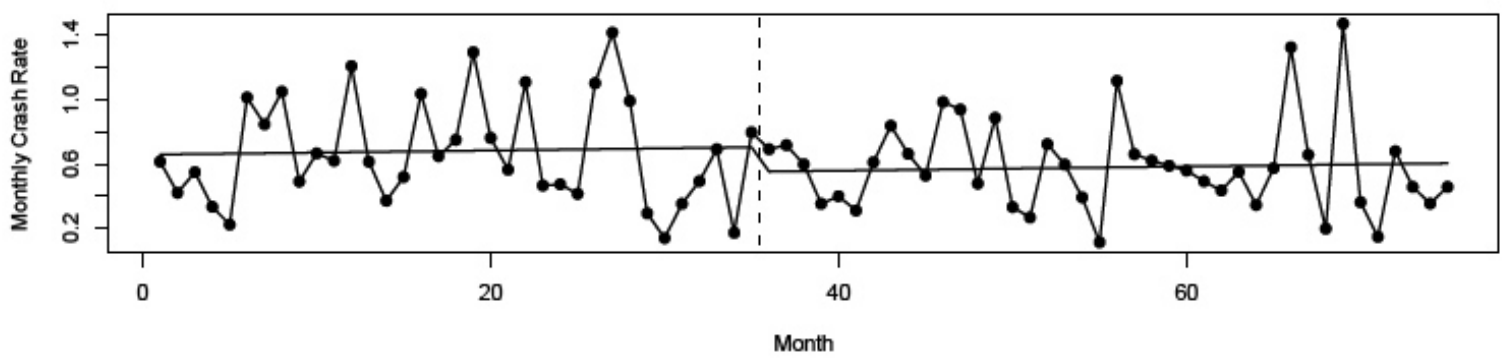

Guilford

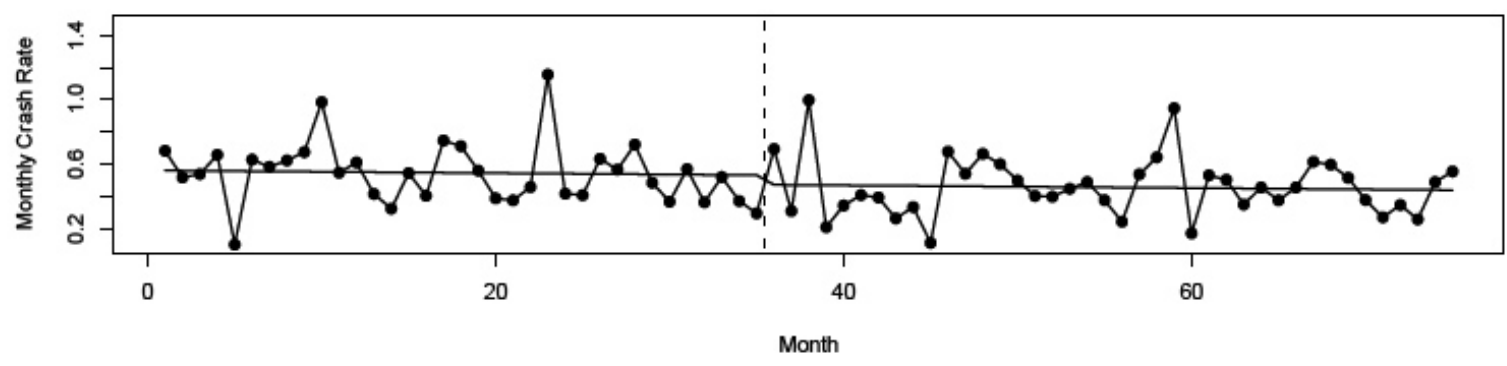

Mecklenburg

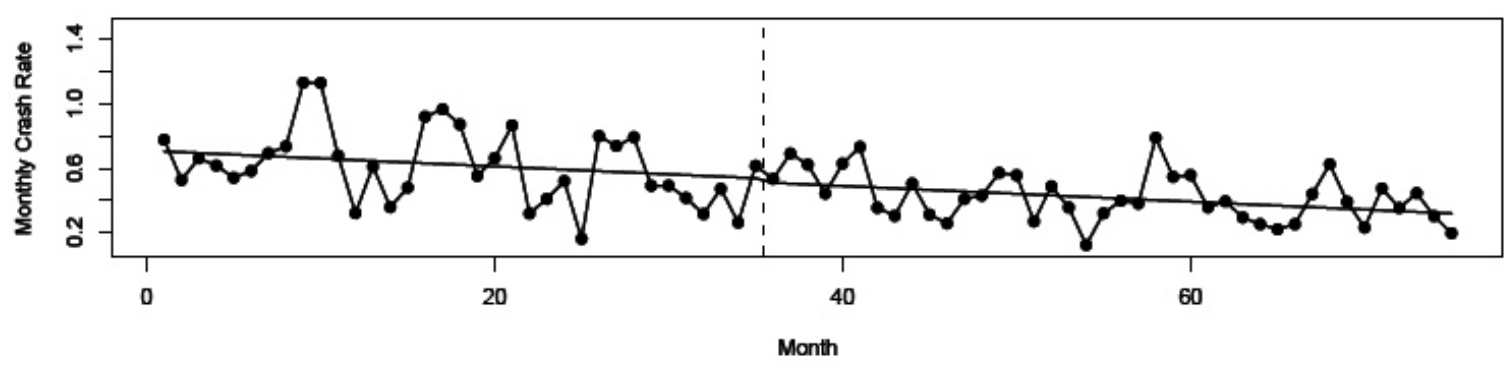

Wake

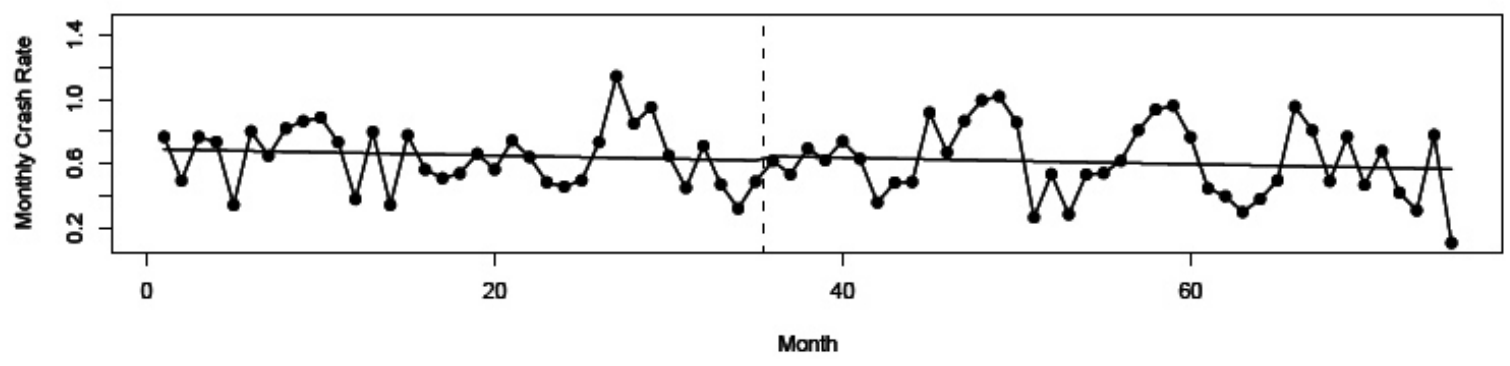

Figure 2a. Adjusted monthly crash rates, 6 am - 9 am, in four NC counties. 

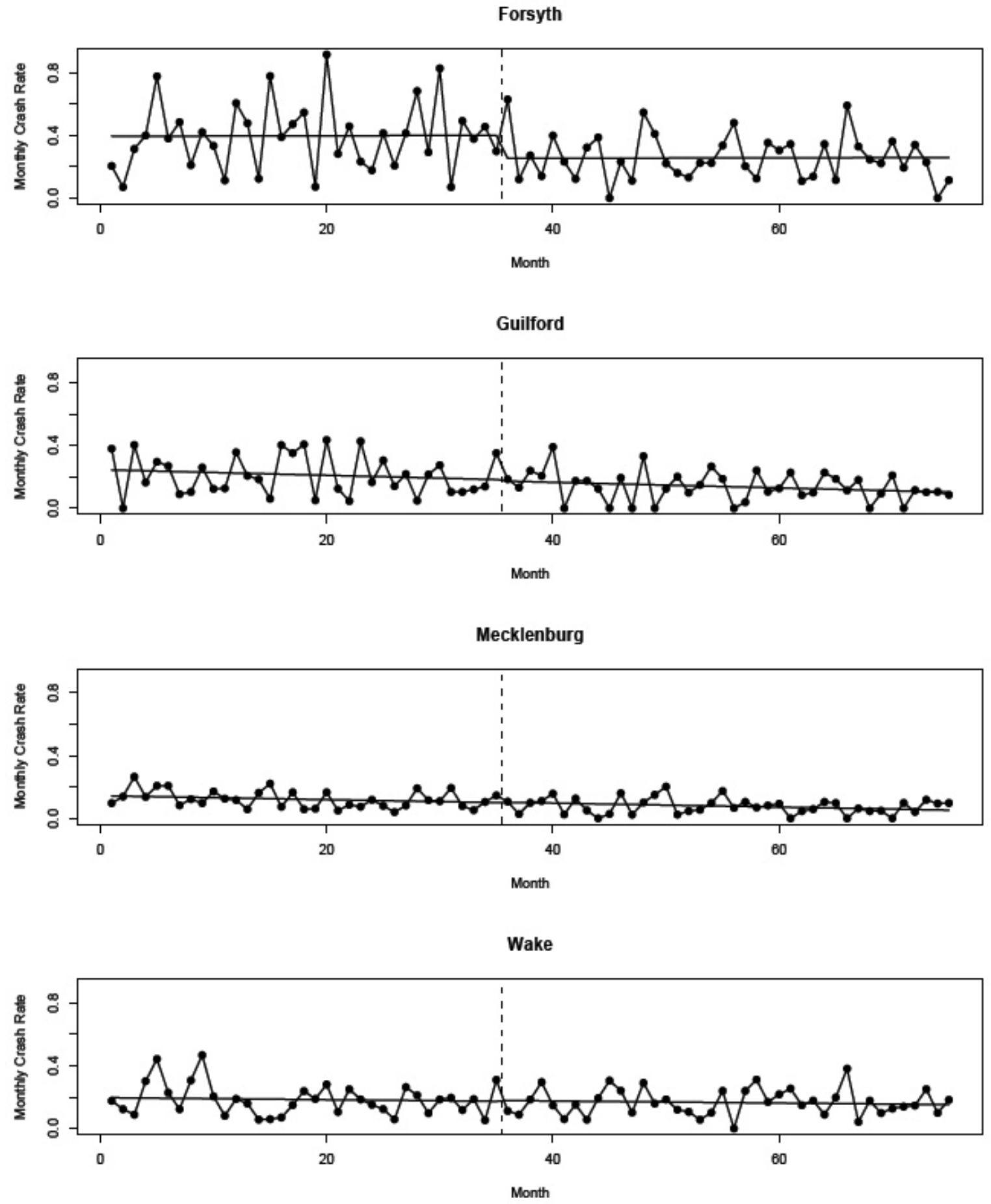

Figure 2b. Adjusted monthly crash rates, 9 am - Noon, in four NC counties. 

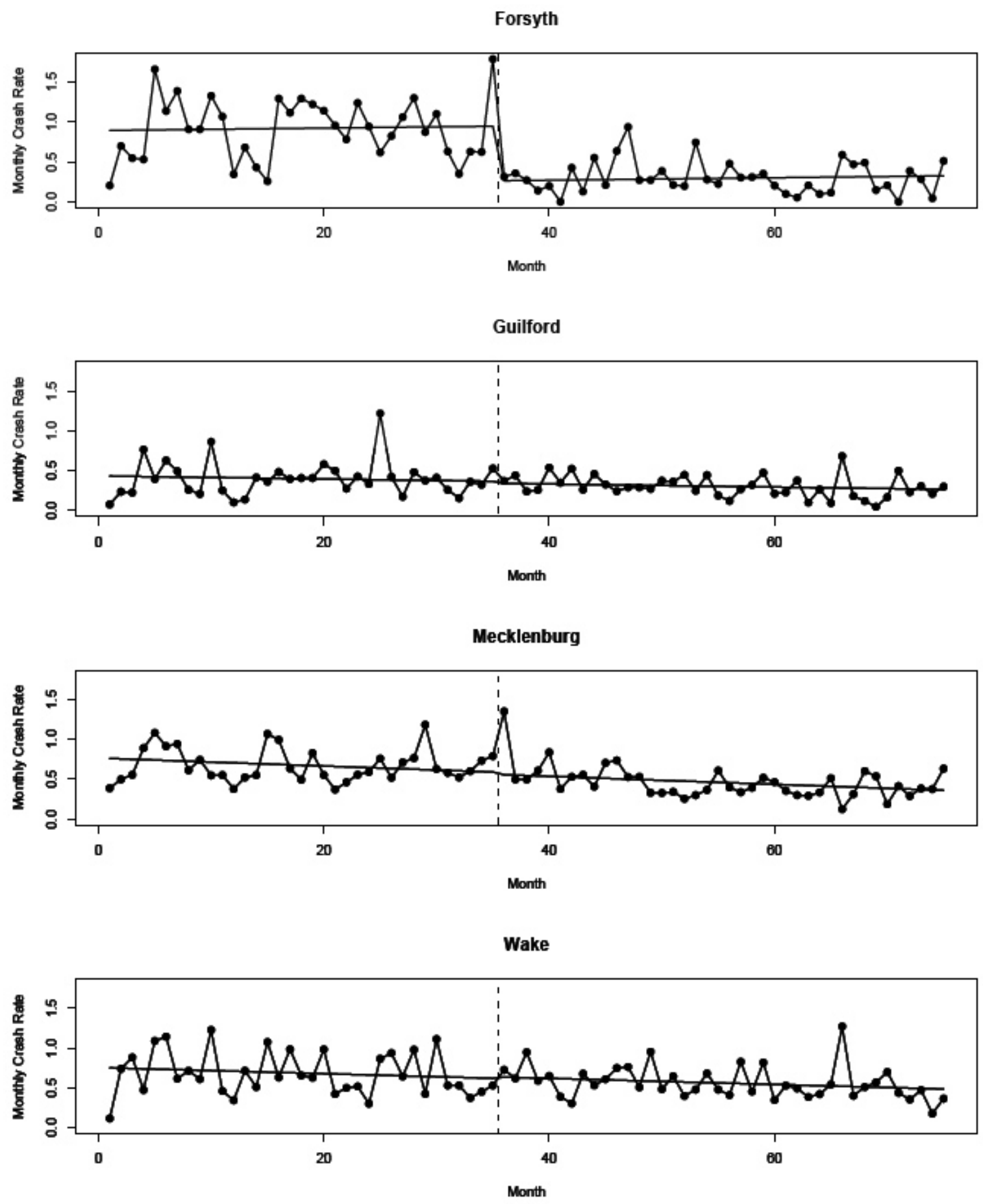

Figure 2c. Adjusted monthly crash rates, Noon - 3 pm, in four NC counties. 
Forsyth

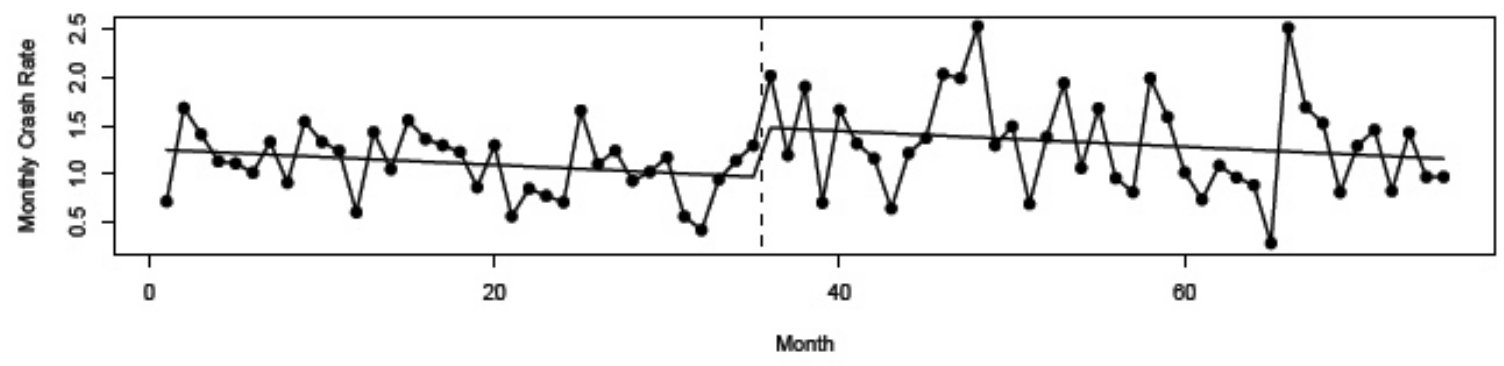

Guilford
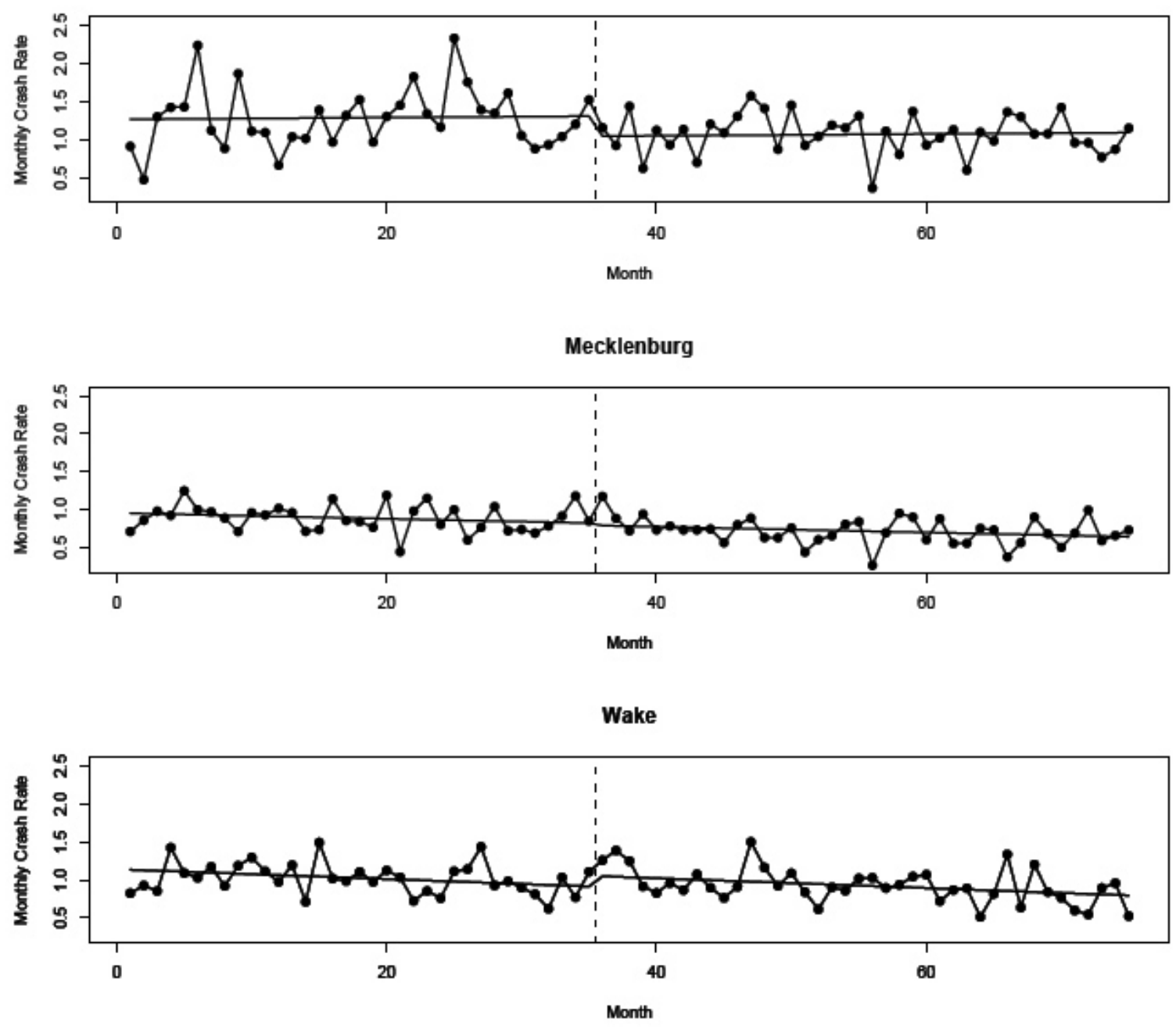

Figure 2d. Adjusted monthly crash rates, 3 pm - 6 pm, in four NC counties. 
Forsyth

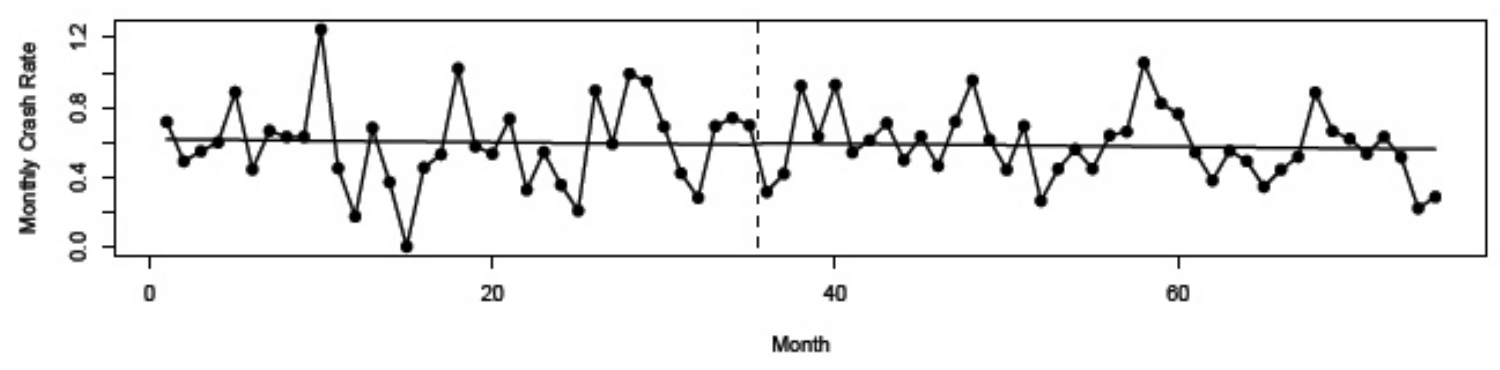

Guilford

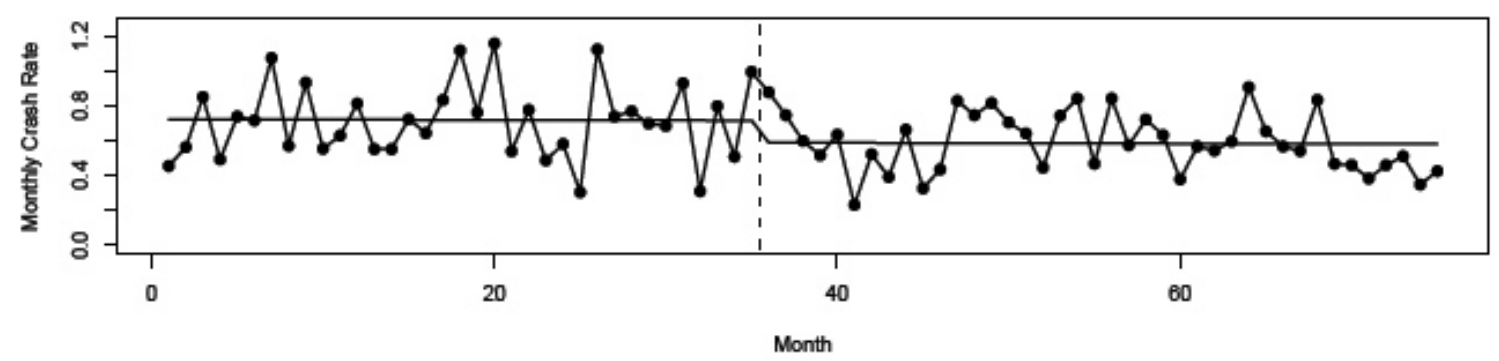

Mecklenburg

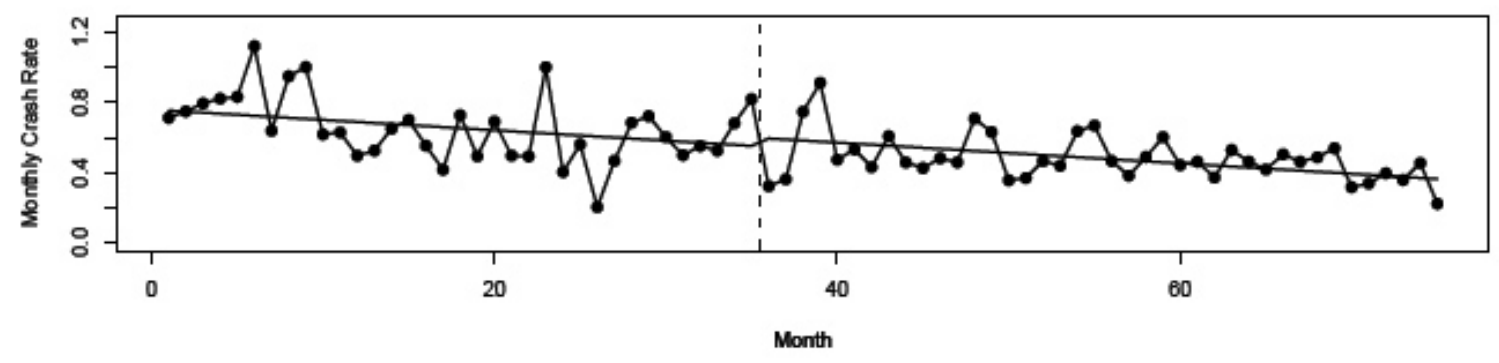

Wake

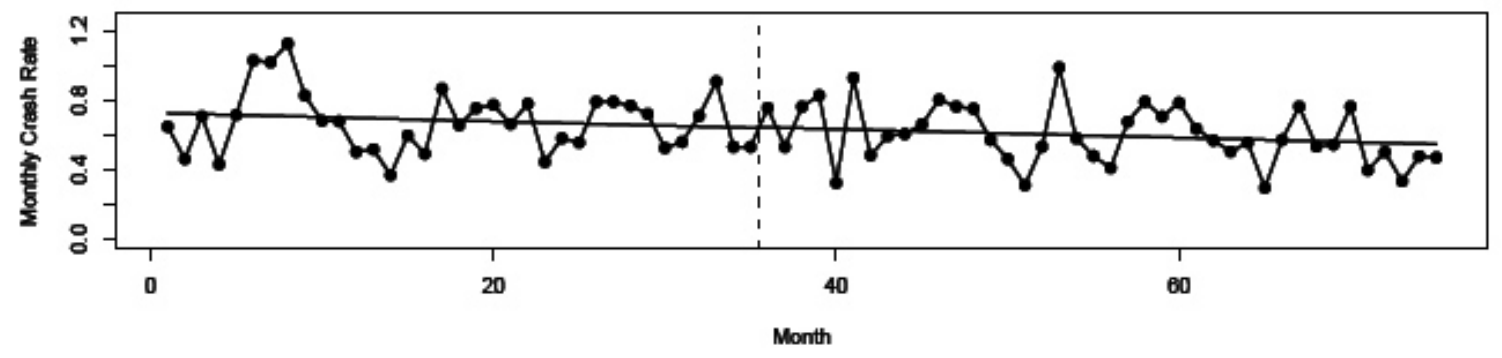

Figure 2e. Adjusted monthly crash rates, 6 pm - 6 am, in four NC counties. 
In each of Figures $2 \mathrm{a}$. - 2c., we see a downward change point for Forsyth County, which is not replicated in any of the other three counties. However, contrary to what would be expected if the change in school start times decreased drowsy driving, the shift is strongest in the noon $-3 \mathrm{pm}$ time period. There is an upward shift in the time period 3 pm - 6 pm (Figure 2d.) for Forsyth County. During the evening and nighttime period from $6 \mathrm{pm}-6 \mathrm{am}$, (Figure 2e.) there is no evidence of any shift.

These results are consistent with a change in the pattern of crashes corresponding to the times when high school age drivers are on the roads. At present, the school day ends at 3:40 pm in Forsyth County high schools. Prior to the policy change the instruction day ended at 2:25 pm. High school parking lots clear out quickly after the final bell, putting a large number of teenage drivers on the roadways within 15-20 minutes. This change in the peak exposure time for high school age drivers resulting from the shift in start (and ending) times provides a parsimonious explanation for the decrease in crashes from noon - 3 pm and the increase after 3 pm.

However, what seems to be more relevant for assessing the effect of the school policy change is that there is an overall decrease at the change point shown in Figure 1. In other words, although there is an increase in crashes between $3 \mathrm{pm}-6 \mathrm{pm}$, this is compensated by a larger overall decrease in crashes over the other three time periods. The fact that this daily pattern is not replicated for any of the other three counties provides some support for the belief that the shift observed in Figure 1 for Forsyth County is a genuine decrease in crash rates, whereas that for Guilford County is probably spurious (and there is no evidence of any change point for the other two counties).

We now examine the statistical significance of these shifts, using ARIMA time series analysis.

Intervention analysis for Forsyth County

The model (5), applied to the full dataset for Forsyth County, yields the results given in Table 4. 
Table 4. Results of model (5) for the time series from Forsyth County, NC.

\begin{tabular}{lcrcrc}
\hline Model & Parameter & Estimate & $\begin{array}{c}\text { Standard } \\
\text { Error }\end{array}$ & t-statistic & $\begin{array}{c}\text { One-sided } \\
p \text {-value }\end{array}$ \\
\hline \hline \multirow{2}{*}{ No Intervention } & $\theta_{1}$ & -0.855 & 0.276 & -3.095 & 0.001 \\
& $\beta_{0}$ & -0.145 & 0.033 & -4.345 & 0.000 \\
& AIC & 142.2 & & & \\
\hline \multirow{2}{*}{ Intervention } & $\theta_{1}$ & -0.826 & 0.229 & -3.611 & 0.000 \\
& $\beta_{0}$ & -0.050 & 0.063 & -0.804 & 0.211 \\
& $\beta_{1}$ & -0.475 & 0.267 & -1.778 & 0.038 \\
& AIC & 141.1 & & & \\
\hline
\end{tabular}

Thus, the model with no intervention shows a statistically significant overall downward trend $\left(\beta_{0}\right)$, but the one with an intervention shows a negative $\beta_{1}$ with a one-sided $p=$ .038 , indicating a drop following the change in school start time. ${ }^{3}$ It is also worth pointing out that the AIC statistic favors the model with an intervention over the one without (lower AIC indicates better fit of the model). ${ }^{4}$

The same model was fitted to the separate time periods with the results shown in Table 5 . For simplicity we report only the $\beta_{1}$ parameter estimates, which measure the size of the shift, under the intervention model.

\footnotetext{
${ }^{3}$ Throughout this report, we have chosen to quote one-sided $p$-values, on the grounds that we are primarily interested in detecting evidence that the change in school start times has decreased the overall rate of crashes among high school age drivers. However, this is not a clear-cut decision; if changes in either direction were of interest, it would be appropriate to use a two-sided test. Two-sided $p$-values are obtained by multiplying the one-sided $p$-values by 2 . In any case, our intention in quoting $p$-values is not to provide an absolute accept-reject criterion, but to guide the reader as to the reliability of a particular effect: the smaller the $p$-values, the stronger the evidence that the increase or decrease in crash rates is real.

${ }^{4}$ Plots of the autocorrelation function (ACF) and partial ACF for the differenced series $y_{t}$ showed significant autocorrelations at lag 10 (which is natural, since this corresponds to the seasonal effect) and also at some other lags, notably 4 and 6 . The corresponding plots for the residuals from the time series model still showed a slightly significant autocorrelation at lag 4. However the Ljung-Box test (which combines the ACF at lags $1,2, \ldots, J$ into a single test statistic) is not significant for any value of $J$ up to 20 . Therefore, we concluded that the model is a reasonable fit to the data.
} 
Table 5. The $\hat{\beta}_{1}$ parameter estimates from model (5) fitted to five different time periods for Forsyth County.

\begin{tabular}{|c|c|c|c|c|}
\hline Time period & $\hat{\beta}_{1}$ & $\begin{array}{l}\text { Standard } \\
\text { Error }\end{array}$ & $t$-statistic & $\begin{array}{c}\text { One-sided } \\
p \text {-value }\end{array}$ \\
\hline $6 a m-9 a m$ & -0.152 & 0.115 & -1.32 & 0.090 \\
\hline 9 am - noon & -0.151 & 0.077 & -1.96 & 0.025 \\
\hline Noon - 3 pm & -0.686 & 0.129 & -5.32 & $<0.001$ \\
\hline $3 p m-6 p m$ & 0.511 & 0.183 & 2.78 & 0.003 \\
\hline $6 p m-6 a m$ & 0.011 & 0.083 & 0.13 & 0.450 \\
\hline
\end{tabular}

The results show a significant decrease in crash rates during 9 am - noon and during noon $-3 \mathrm{pm}$, a significant increase during $3 \mathrm{pm}-6 \mathrm{pm}$, and no statistically significant shift during 6 am - 9 am or 6 pm - 6 am.

\section{Application to Guilford County}

The initial set of results for Guilford County corresponding to the full 6 am $-6 \mathrm{pm}$ time period is given in Table 6. Results based on 3-hour sub-periods are given in Table 7.

The main difference here is that although the intervention parameter $\beta_{1}$ is again negative, the one-sided $p$-value (.076) is well beyond the conventional level of statistical significance used in hypothesis testing. The sub-period values are not statistically significant except for the downward shift in the $3 \mathrm{pm}-6 \mathrm{pm}$ period. This could well be spurious, but needs to be noted.

Table 6. Results of model (5) for the time series from Guilford County.

\begin{tabular}{lcrcrc}
\hline Model & Parameter & Estimate & $\begin{array}{c}\text { Standard } \\
\text { Error }\end{array}$ & t-statistic & $\begin{array}{c}\text { One-sided } \\
p \text {-value }\end{array}$ \\
\hline \hline \multirow{2}{*}{ No Intervention } & $\theta_{1}$ & -1.000 & 0.280 & -3.571 & 0.000 \\
& $\beta_{0}$ & -0.105 & 0.029 & -3.617 & 0.000 \\
& AIC & 131.3 & & & \\
\hline \multirow{2}{*}{ Intervention } & $\theta_{1}$ & -1.000 & 0.276 & -3.621 & 0.000 \\
& $\beta_{0}$ & -0.033 & 0.058 & -0.579 & 0.281 \\
& $\beta_{1}$ & -0.358 & 0.250 & -1.431 & 0.076 \\
& AIC & 131.2 & & & \\
\hline
\end{tabular}




\section{Table 7. The $\hat{\beta}_{1}$ parameter estimates from model (5) fitted to five different time periods for Guilford County.}

\begin{tabular}{lcccc}
\hline Time period & $\hat{\beta}_{1}$ & $\begin{array}{c}\text { Standard } \\
\text { Error }\end{array}$ & $t$-statistic & $\begin{array}{c}\text { One-sided } \\
p \text {-value }\end{array}$ \\
\hline \hline 6 am - 9 am & -0.059 & 0.082 & -0.73 & 0.230 \\
9 am - noon & -0.005 & 0.038 & -0.13 & 0.450 \\
Noon - 3 pm & -0.013 & 0.079 & -0.16 & 0.440 \\
3 pm - 6 pm & -0.265 & 0.150 & -1.76 & 0.039 \\
6 pm - 6 am & -0.127 & 0.087 & -1.47 & 0.070 \\
\hline
\end{tabular}

Note. The time series model is again (5), except for 9 am noon, for which the model is (4) with $P=q=0, p=Q=1$, i.e. we included an autoregressive non-seasonal component of order 1 as well as the moving average seasonal component of order 1 , since this model provided a better fit for this dataset.

\section{Application to Mecklenburg County}

The results for the full time period for Mecklenburg County are given in Table 8 and the results for five sub-periods are given in Table 9. There is no evidence of an intervention effect, at any time of day.

Table 8. Results of model (5) for the time series from Mecklenburg County.

\begin{tabular}{lcrcrc}
\hline Model & Parameter & Estimate & $\begin{array}{c}\text { Standard } \\
\text { Error }\end{array}$ & $t$-statistic & $\begin{array}{c}\text { One-sided } \\
p \text {-value }\end{array}$ \\
\hline \hline No Intervention & $\theta_{1}$ & -0.631 & 0.141 & -4.481 & 0.000 \\
& $\beta_{0}$ & -0.167 & 0.024 & -7.087 & 0.000 \\
& $\mathrm{AIC}$ & 66 & & & \\
\hline \multirow{2}{*}{ Intervention } & $\theta_{1}$ & -0.634 & 0.141 & -4.495 & 0.000 \\
& $\beta_{0}$ & -0.154 & 0.037 & -4.19 & 0.000 \\
& $\beta_{1}$ & -0.064 & 0.147 & -0.436 & 0.331 \\
& $\mathrm{AIC}$ & 67.8 & & & \\
\hline
\end{tabular}


Table 9. The $\hat{\beta}_{1}$ parameter estimates from model (5) fitted to five different time periods for Mecklenburg County.

\begin{tabular}{lcrrr}
\hline Time period & $\hat{\beta}_{1}$ & $\begin{array}{c}\text { Standard } \\
\text { Error }\end{array}$ & $t$-statistic & $\begin{array}{c}\text { One-sided } \\
p \text {-value }\end{array}$ \\
\hline \hline 6 am - 9 am & -0.021 & 0.071 & -0.29 & 0.39 \\
9 am - noon & 0.003 & 0.024 & 0.13 & 0.45 \\
Noon - 3 pm & -0.028 & 0.078 & -0.36 & 0.36 \\
$3 \mathrm{pm}-6 \mathrm{pm}$ & -0.027 & 0.080 & -0.34 & 0.36 \\
$6 \mathrm{pm}-6 \mathrm{am}$ & 0.048 & 0.063 & 0.77 & 0.22 \\
\hline
\end{tabular}

\section{Application to Wake County}

The full period results for Wake County are given in Table 10 and the five sub-periods in Table 11. There is no evidence of any intervention effect, though it's marginal for $3 \mathrm{pm}-$ $6 \mathrm{pm}$.

Table 10. Results of model (5) for the time series from Wake County.

\begin{tabular}{lcrrrr}
\hline Model & Parameter & Estimate & $\begin{array}{c}\text { Standard } \\
\text { Error }\end{array}$ & $t$-statistic & $\begin{array}{c}\text { One-sided } \\
p \text {-value }\end{array}$ \\
\hline \hline \multirow{2}{*}{ No Intervention } & $\theta_{1}$ & -0.692 & 0.178 & -3.894 & 0.000 \\
& $\beta_{0}$ & -0.092 & 0.026 & -3.519 & 0.000 \\
& AIC & 89.8 & & & \\
\hline \multirow{2}{*}{ Intervention } & $\theta_{1}$ & -0.700 & 0.176 & -3.980 & 0.000 \\
& $\beta_{0}$ & -0.127 & 0.043 & -2.924 & 0.002 \\
& $\beta_{1}$ & 0.177 & 0.178 & 0.992 & 0.160 \\
& AIC & 90.8 & & & \\
\hline
\end{tabular}

Table 11. The $\hat{\beta}_{1}$ parameter estimates from model (5) fitted to five different time periods for Wake County.

\begin{tabular}{lccrr}
\hline Time period & $\hat{\beta}_{1}$ & $\begin{array}{c}\text { Standard } \\
\text { Error }\end{array}$ & $t$-statistic & $\begin{array}{c}\text { One-sided } \\
p \text {-value }\end{array}$ \\
\hline \hline 6 am - 9 am & 0.024 & 0.084 & 0.29 & 0.39 \\
9 am - noon & 0.005 & 0.041 & 0.13 & 0.45 \\
noon-3 pm & 0.015 & 0.057 & 0.25 & 0.49 \\
3 pm - 6pm & 0.137 & 0.084 & 1.63 & 0.052 \\
6 pm - 6 am & 0.005 & 0.072 & 0.073 & 0.47 \\
\hline Note. The model for noon - 3 pm was based on (4) with $P=q=0$, \\
$p=Q=1$, which provided a better fit to the data.
\end{tabular}


Table 12 provides a summary of the intervention parameter estimate $\left(\hat{\beta}_{1}\right)$, from the fitted model, and its statistical significance for five daily time periods in each of the four counties.

\section{Table 12. Summary table of the $\hat{\beta}_{1}$ parameter from model (5) fitted to five different time periods for Forsyth and 3 comparison Counties.}

\begin{tabular}{lllcr}
\hline Time period & Forsyth & Guilford & Mecklenburg & Wake \\
\hline \hline 6 am - 9 am & -0.152 & -0.059 & -0.021 & 0.024 \\
9 am - noon & $-0.151^{*}$ & -0.005 & 0.003 & 0.005 \\
Noon - 3 pm & $-0.686^{* *}$ & -0.013 & -0.028 & 0.015 \\
3 pm - 6 pm & $0.511^{* *}$ & $-0.265^{*}$ & -0.027 & 0.137 \\
6 pm - 6 am & 0.011 & -0.127 & 0.048 & 0.005 \\
\hline${ }^{*}$ 1-sided $p<.05,{ }^{* *}$ 1-sided $\mathrm{p}<.01$ & &
\end{tabular}

Hour by hour analysis of Forsyth County data

To better understand the variation by hour of day, the data from Forsyth County were broken up into single-hour analyses, from 6 am (meaning the hour between 6 am and 7 am) through to $11 \mathrm{pm} .{ }^{5}$ The data are plotted in Figure 3.

The estimated changes in population-adjusted crash rates at the time of the school schedule change $\left(\hat{\beta}_{1}\right)$, together with associated standard errors, $t$-statistics and onesided $p$-values, are given in Table 13.

\footnotetext{
${ }^{5}$ Outside those hours, there are too few crashes in total for the analysis to be meaningful. Even at the 6 am and 11 pm hours, a large fraction of the observed monthly crash rates are 0 .
} 

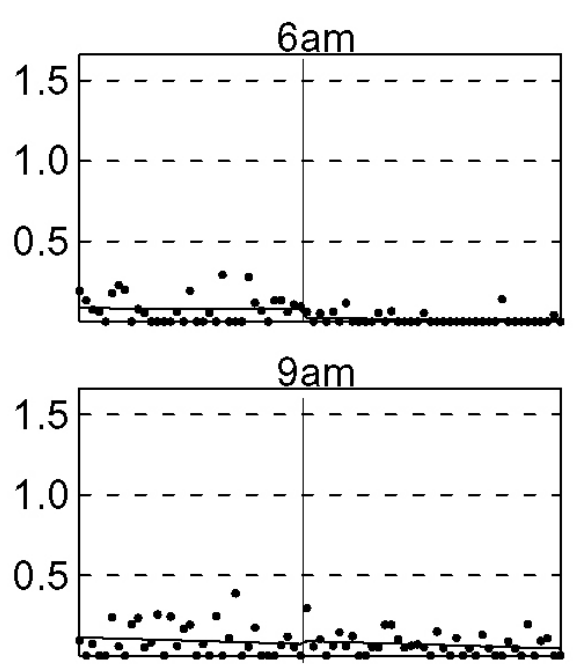

$12 \mathrm{pm}$
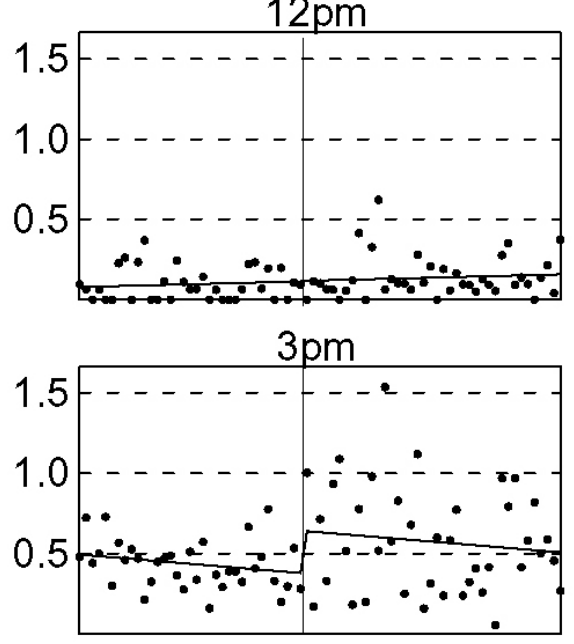

$6 \mathrm{pm}$

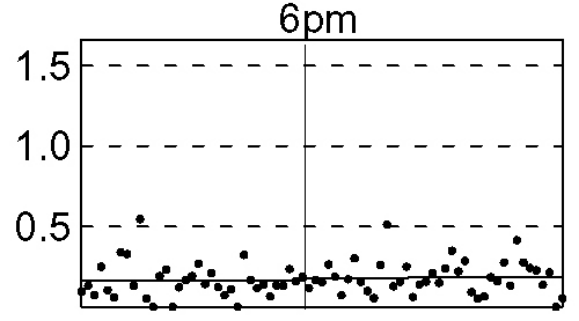

$9 \mathrm{pm}$

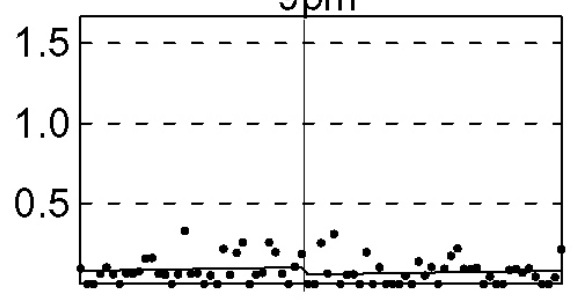

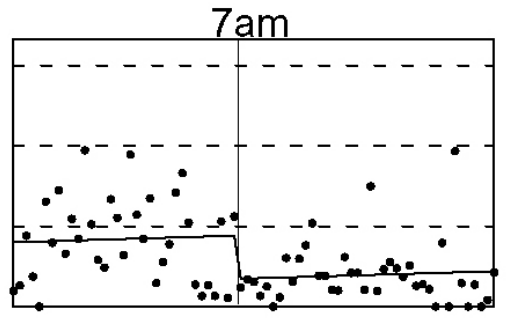

$10 \mathrm{am}$

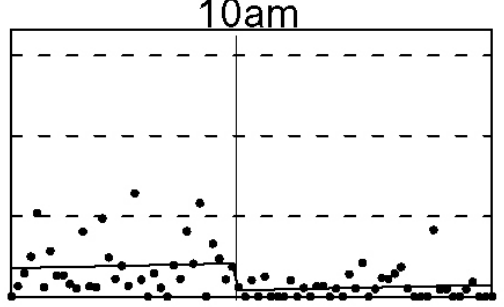

$1 \mathrm{pm}$
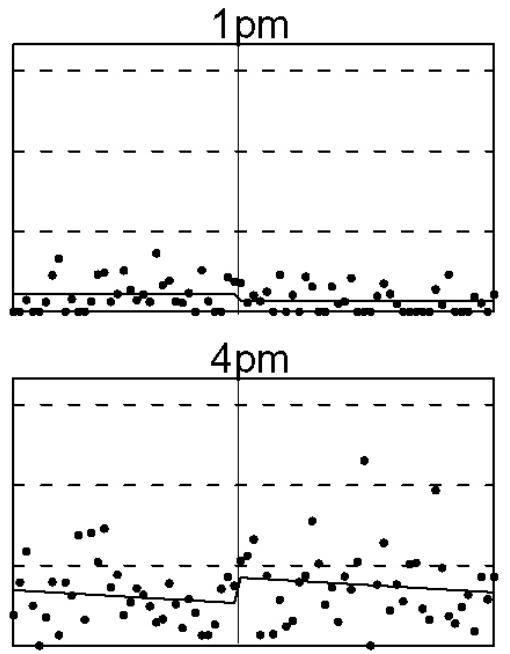

$7 \mathrm{pm}$

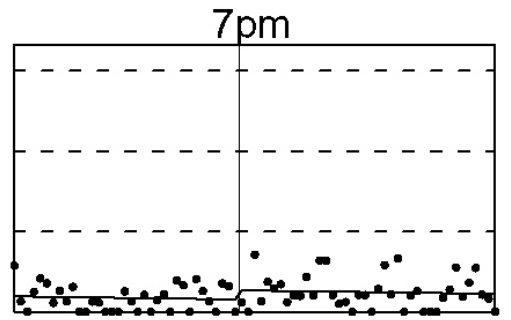

$10 \mathrm{pm}$

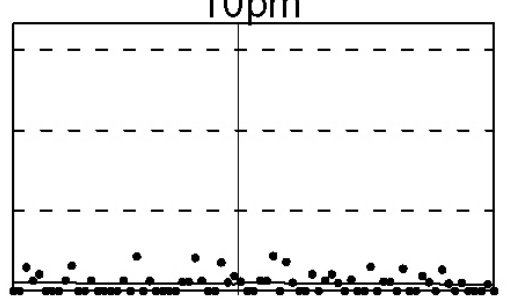

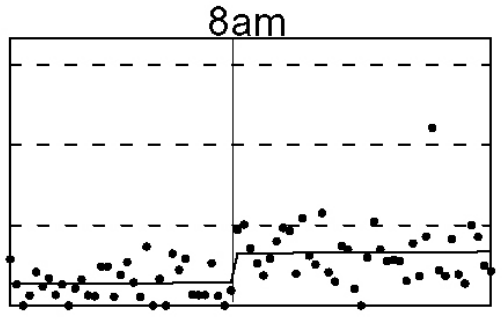

$11 \mathrm{am}$

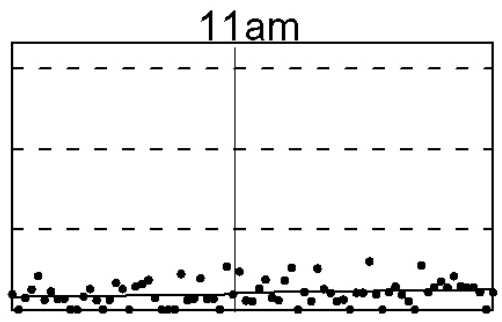

$2 \mathrm{pm}$

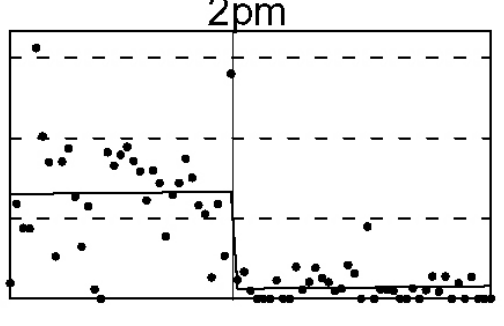

$5 \mathrm{pm}$

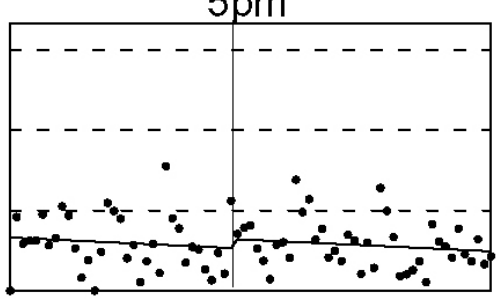

$8 \mathrm{pm}$

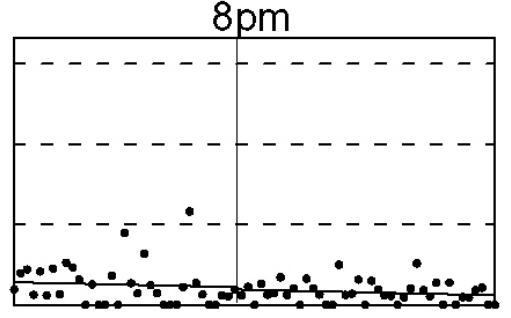

$11 \mathrm{pm}$

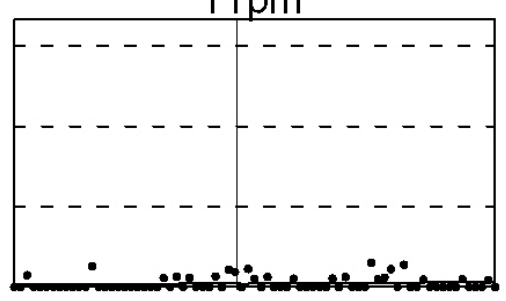

Figure 3. Adjusted monthly crash rates, by single hour, Forsyth County, NC. 
Table 13. Hour by hour analyses for Forsyth County.

\begin{tabular}{lrrrr}
\hline Hour & \multicolumn{1}{c}{$\hat{\beta}_{1}$} & $\begin{array}{c}\text { Standard } \\
\text { Error }\end{array}$ & $\begin{array}{r}t \text {-statistic } \\
\text { Oresalue }\end{array}$ \\
\hline \hline $6 \mathrm{am}$ & -0.060 & 0.031 & -1.922 & 0.027 \\
$7 \mathrm{am}$ & -0.287 & 0.107 & -2.691 & 0.004 \\
$8 \mathrm{am}$ & 0.194 & 0.066 & 2.925 & 0.002 \\
$9 \mathrm{am}$ & 0.020 & 0.043 & 0.474 & 0.318 \\
$10 \mathrm{am}$ & -0.182 & 0.062 & -2.948 & 0.002 \\
$11 \mathrm{am}$ & 0.012 & 0.038 & 0.307 & 0.379 \\
Noon & 0.003 & 0.055 & 0.047 & 0.481 \\
$1 \mathrm{pm}$ & -0.044 & 0.043 & -1.016 & 0.155 \\
$2 \mathrm{pm}$ & -0.645 & 0.118 & -5.472 & 0.000 \\
$3 \mathrm{pm}$ & 0.277 & 0.123 & 2.246 & 0.012 \\
$4 \mathrm{pm}$ & 0.171 & 0.106 & 1.611 & 0.054 \\
$5 \mathrm{pm}$ & 0.061 & 0.069 & 0.877 & 0.190 \\
$6 \mathrm{pm}$ & 0.017 & 0.048 & 0.360 & 0.359 \\
$7 \mathrm{pm}$ & 0.061 & 0.044 & 1.378 & 0.084 \\
$8 \mathrm{pm}$ & -0.016 & 0.049 & -0.333 & 0.370 \\
$9 \mathrm{pm}$ & -0.049 & 0.041 & -1.18 & 0.119 \\
$10 \mathrm{pm}$ & 0.010 & 0.028 & 0.340 & 0.367 \\
$11 \mathrm{pm}$ & -0.003 & 0.020 & -0.157 & 0.438 \\
\hline
\end{tabular}

For the 6 am and 7 am hours, there is a statistically significant decrease, which is partly balanced by an increase in the 8 am hour. These results are directly interpretable as due to the schedule change, in the obvious sense that if crashes are going to occur as teens are driving to school, they are more likely to occur close to the school start time. They do not suggest that students overall are safer as a result of the schedule change. Likewise, there is a statistically significant decrease during the $2 \mathrm{pm}$ hour, matched by increases in the $3 \mathrm{pm}$ and $4 \mathrm{pm}$ hours, but note that the $2 \mathrm{pm}$ change is by far the biggest change in magnitude during the entire day. The one other statistically significant result is that there is a drop in crash rates during the 10am hour, which is hard to explain.

Adding up all the $\hat{\beta}_{1}$ values in Table 13 , we find the result -0.46 , is essentially identical to the result reported above for the full daytime crash series $(-0.475)$. Since the overall mean population-adjusted crash rate is 3.34 , this represents about a $14 \%$ drop in the overall crash rate as a result of the schedule change, but with the same caveats as noted earlier about the statistical significance of that result. 
The analyses reported here for the single hour crash series used the same ARIMA model as in the main, full-day analysis. Because of the smaller number of crashes during one-hour windows, it is more questionable whether such a model is actually appropriate (e.g. the normal distribution is more likely justified as an approximation when sample sizes are large). However, these analyses were checked using the LjungBox test for residual autocorrelation and looking for outliers as a test of the normal distribution; there is no evidence from those tests that the analyses are unreasonable.

\section{ANALYSIS AND RESULTS FOR KENTUCKY}

Changes of 60 minutes or more in school start times have been relatively rare in school districts large enough to support an analysis of teenage driver crashes. To take advantage of an additional natural experiment, created when Fayette County, Kentucky introduced a later school start time in the fall of 1998, we analyzed Kentucky crash data as well. As noted above, several limitations of the Danner \& Phillips (2008) study design cast some doubt on whether their findings accurately represent the effect of the change in school start time.

Kentucky crash data for 1997 through 2005 were obtained from the NHTSA State Data System. Age-specific population data were obtained from U.S. Census annual population estimates. Days that schools were in session were obtained from historical records maintained by state and county school officials.

As a comparison for Fayette County, we selected Jefferson County. Jefferson and Fayette Counties respectively contain the cities of Louisville and Lexington, the only two large cities in Kentucky. The population per square mile in 2000 was 916 in Fayette County and 1801 in Jefferson County. Although Jefferson County is substantially more populous and more densely populated, these two counties differ dramatically from the rest of Kentucky, with a population density of 79 persons per square mile as of 2000). Although the greater density of Jefferson County might be expected to produce a higher overall crash rate, it is otherwise far more comparable to Fayette County than any other in the state. ${ }^{6}$

\footnotetext{
${ }^{6}$ One other possibility was Kenton County, which had a similar population density to Fayette County in 2000. However, it was judged an unacceptable comparison because the total population in 2000 was only about 150,000,
} 


\section{Application to Fayette County}

These data were compiled in the same way as the North Carolina data, using a 10month year and calculating crash rates per school day for 16-17 year-old drivers, adjusted for population. This provides 90 data points -15 before the change in start time and 75 afterward. Table 14 shows the annual estimated 16-17 year-old population, obtained from U.S. Census estimates series, in the years studied for the two counties considered.

Table 14. Populations of 16- and 17-year-olds, in Fayette (intervention) and Jefferson (comparison) Counties, Kentucky for the years of study.

\begin{tabular}{rrr}
\hline Year & Fayette & Jefferson \\
\hline \hline 1997 & 5749 & 18810 \\
1998 & 5708 & 18399 \\
1999 & 5653 & 18092 \\
2000 & 5903 & 18311 \\
2001 & 5876 & 17996 \\
2002 & 5846 & 17827 \\
2003 & 5838 & 17963 \\
2004 & 5714 & 18063 \\
2005 & 5967 & 18346 \\
\hline
\end{tabular}

Inspection of the initial time-series plots (see Figures $4 a \& 4 b)$ suggested the following:

- 6 am - 6 pm: slight evidence of increasing crash rate after the change.

- 6 pm - midnight: no evidence of any change

- 6 am - 9 am: slight evidence of increasing crash rate after the change.

- 9 am - noon: possible very slight increase after the change.

- Noon - 3 pm: apparent decrease in crash rate after the change

- 3 pm - 6 pm: apparent increase in crash rate after the change 
All Crashes
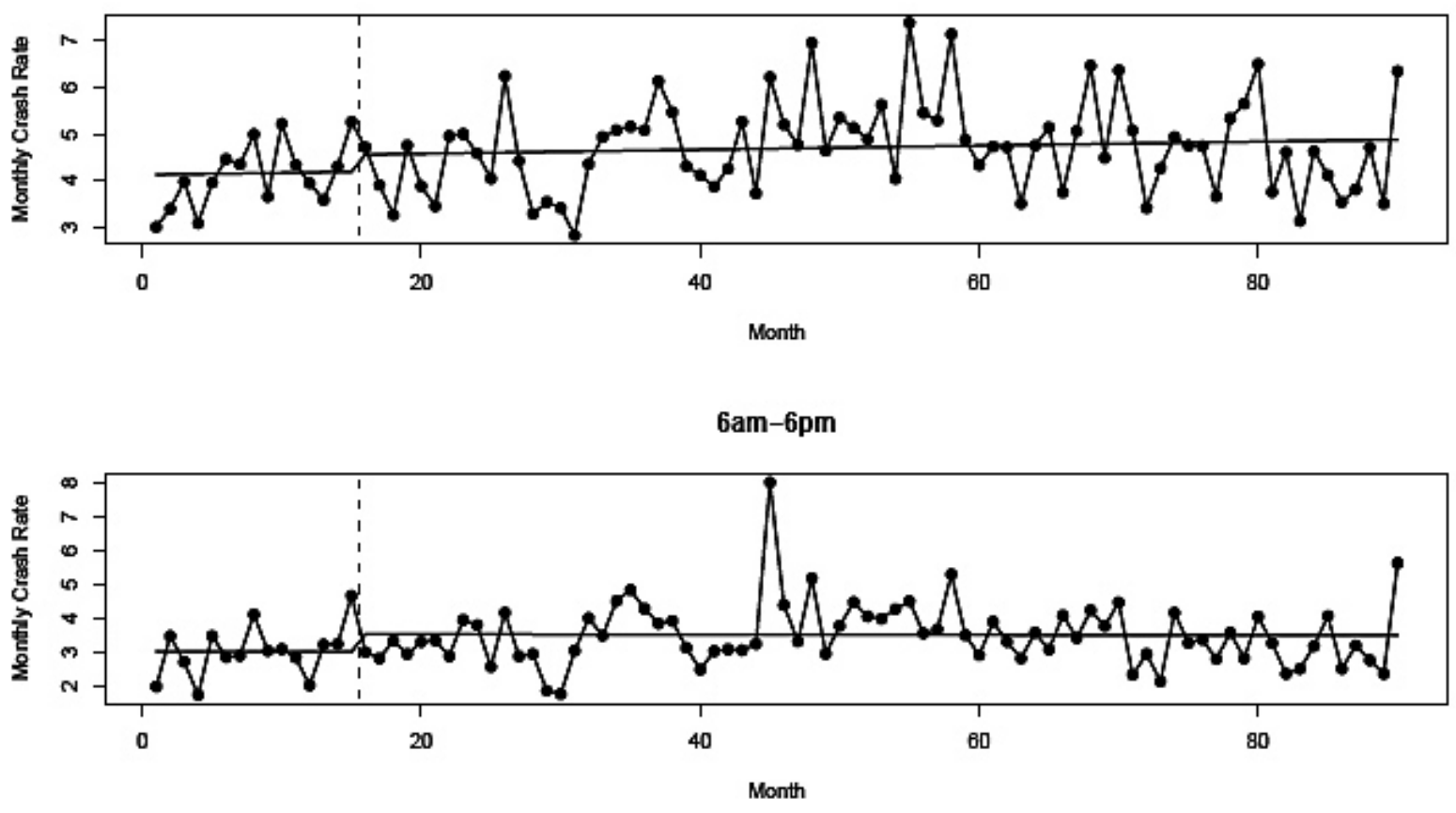

6pm-midnight

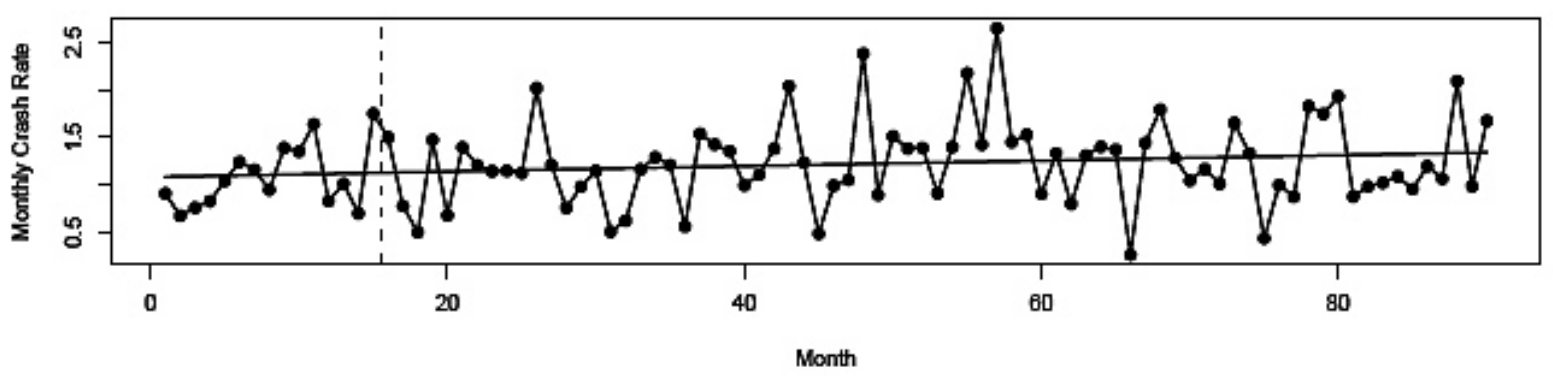

Figure 4a. Adjusted monthly crash rates, three time periods, Fayette County, KY. 
As with the North Carolina results, our main interest is in determining the statistical significance of possible effects through an ARIMA analysis. We do this separately for the full day and for five smaller time blocks (excluding $6 \mathrm{pm}$ - midnight, since there was no indication of any change and midnight -6 am during which there were too few crashes to analyze). Crash data were only available for 15 months prior to the change in school start time in Fayette County (as of August 1999). Partly as a result of this short pre-intervention period, fitting the data series was more difficult than in North Carolina.

\section{Full Day Analysis}

Initially we tried the same model as used for most of the North Carolina analyses, i.e. first difference the series as in equation (2), then fit an ARIMA model of form (5). However, both before and after the model fitting, the time series showed a significant autocorrelation at lag 3 . To remove this, we attempted several time series models with varying $p$ and $q$ in the range $0-3$. The AIC criterion led to an optimal model fit of $p=2, q$ $=3$ and corresponding to that, we find for the estimated change point $\hat{\beta}_{1}=.028$ with a standard error of .506. Although the estimated shift is (slightly) positive, it is not statistically significant.

It should be pointed out that the final result is somewhat sensitive to the choice of time series orders $p$ and $q$. For example, a model with $p=3, q=0$ seems satisfactory as judged by the Ljung-Box test on the residuals, but results in an estimate $\hat{\beta}_{1}=-.414$, with a standard error .554. So in this case, we get a negative estimate of the shift, implying a reduction in crash rates, but it is also not statistically significant. In fact, none of the time series models, for varying $p$ and $q$, produced a statistically significant value of $\hat{\beta}_{1}$, either positive or negative. Therefore, it seems safe to conclude that there is no evidence of an overall shift due to the change in school start times. 
6am-9am
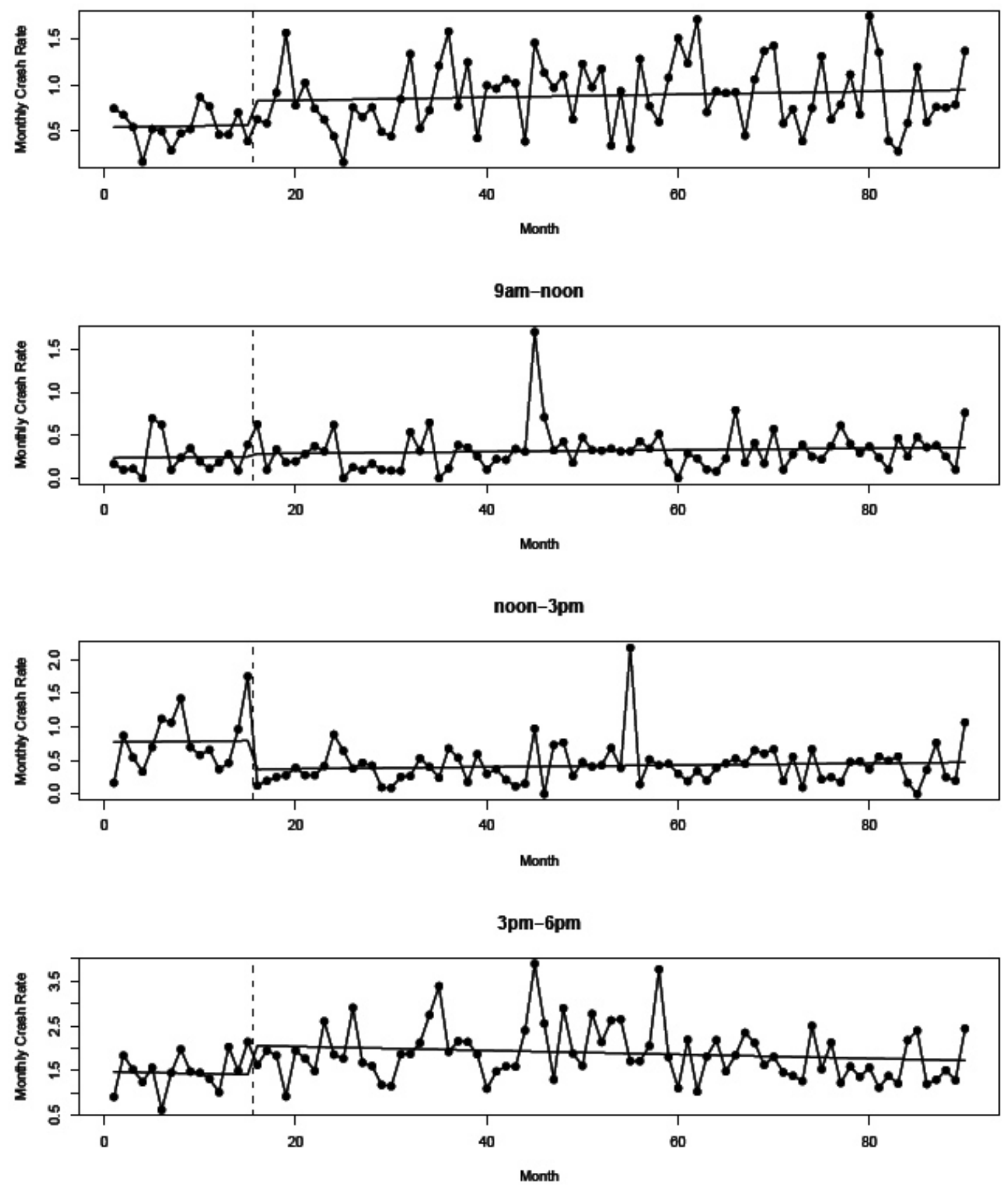

Figure 4b. Adjusted monthly crash rates, four time periods, Fayette County, KY. 
6 am - 6 pm Analysis

For this series we used the same ARIMA model as in the North Carolina data series ( $p$ $=P=q=0, Q=1)$ and found $\hat{\beta}_{1}=0.487$ with a standard error $0.331(t=1.45$, one sided $p=.07)$. In this case the ACF plot of the residuals show a significant autocorrelation at lag 13; this is almost confirmed by the Ljung-Box test ( $p$-value for the Ljung-Box test is .054 at $J=13$ ). Attempting to improve this by trying other time series models, as was done for the full day series above, did not improve the situation.

However, we can also see from the plot of this series in Figure 4a. that there is an outlier in observation 45 (May 2001). We adjusted this by setting observation 45 equal to the second largest value in the data series (observation 90) and repeating the analysis. In this case there is less evidence of autocorrelation in the residuals and the apparent change point effect is reduced $\left(\hat{\beta}_{1}=.340\right.$, standard error $=.320$, one-sided $p=$ .14). Trying alternative ARIMA model orders for this series did not substantially change that conclusion.

Thus, for this series we continue to see slight evidence for a positive shift (increase in crashes after the change in school start time), but it is not statistically significant.

Results of the analyses for each of the daily time blocks shown in Figure 4b. are summarized in Table 15.

Table 15. Summary of separate time period analyses, model (5) results for Fayette County KY.

\begin{tabular}{lcccc}
\hline Time period & $\hat{\beta}_{1}$ & $\begin{array}{c}\text { Standard } \\
\text { Error }\end{array}$ & $t$-statistic & $\begin{array}{c}\text { One-sided } \\
p \text {-value }\end{array}$ \\
\hline \hline $6 \mathrm{am}-9 \mathrm{am}$ & 0.261 & 0.118 & 2.21 & 0.014 \\
$9 \mathrm{am}-$ noon & -0.034 & 0.085 & 0.40 & $>0.500$ \\
Noon - 3 pm & -0.425 & 0.117 & 3.63 & $<0.001$ \\
$3 \mathrm{pm}-6 \mathrm{pm}$ & 0.651 & 0.200 & 3.26 & $<0.001$ \\
$6 \mathrm{pm}-6 \mathrm{am}$ & -0.004 & 0.162 & 0.03 & $>0.500$ \\
\hline
\end{tabular}

There were outliers in several of the series summarized in Figure $4 \mathrm{~b}$ and Table 15. Removing the outlier at month 45 in the $9 \mathrm{am}$ - noon series by setting it equal to the second largest value in the series results in a reduced estimate of $\hat{\beta}_{1}=0.005$, s.e. $=$ 0.068 . Setting outlier at observation 55 in the Noon $-3 \mathrm{pm}$ series equal to the overall 
mean of the series resulted in $\hat{\beta}_{1}=-0.460$, s.e. $=0.098, t=-4.7$, one-sided $p<0.001$. There is also a suspicion of a second outlier at observation 15 in this series, i.e., immediately before the change point, but this does not appear so strongly as an outlier in the residuals from the time series model. Only observation 55 is flagged as an outlier by, for example, the standard Tukey outlier identification procedure applied to the residuals. Therefore, we did not treat observation 15 as an outlier.

In the $3 p m-6 p m$ series there remained a troublesome autocorrelation at lag 13 , that could not be explained away as the result of an outlier (the Ljung-Box test at $J=13$ has a $p$-value of .032). To accommodate this, the following alternative model was fitted (of $\mathrm{MA}(13)$ form with most coefficients set to 0 ):

$$
y_{t}-\beta_{0}-\beta_{1} z_{t}=\left(1+\theta_{10} B^{10}+\theta_{13} B^{13}\right) \varepsilon_{t}
$$

In (6), we find $\hat{\beta}_{1}=0.673$, standard error .190 , so the general result is the same as reported for model (5), in the sense that there is a substantial, statistically significant positive shift in crashes during the $3 \mathrm{pm}-6 \mathrm{pm}$ time period.

In summary, there is a less clear pattern of change in crashes for Fayette County, KY than was seen in Forsyth County, NC. Nonetheless, there is some consistency. The substantial decrease from Noon $-3 \mathrm{pm}$ and the increase from $3-6 \mathrm{pm}$ are to be expected, given that school release time was delayed until after $3 \mathrm{pm}$ by the altered start time. On the other hand, the small increase from 6 am - 9 am was not expected and there is no readily available explanation for this change.

\section{Comparison County Analysis}

Plots of adjusted crash rates for Jefferson County for daytime and nighttime blocks are shown in Figure 5. Unfortunately, the Jefferson County data contain an artifact which precludes a meaningful comparison with Fayette County. As can be seen, there is a substantial drop in adjusted Jefferson County crash rates early in the series, immediately before the date when school start times changed in Fayette County, but the crash rate rises again sharply after that date. No natural explanation comes to mind for this anomaly. It appears to be the result of a temporary disruption in crash reporting for Jefferson County, as this dip is present for all crashes, not merely those of young drivers. In any case, the concentration of this anomaly in the already short pre- 
intervention period prevents a useful comparison between the two counties. Therefore, we did not attempt the formal time series analysis for Jefferson County.
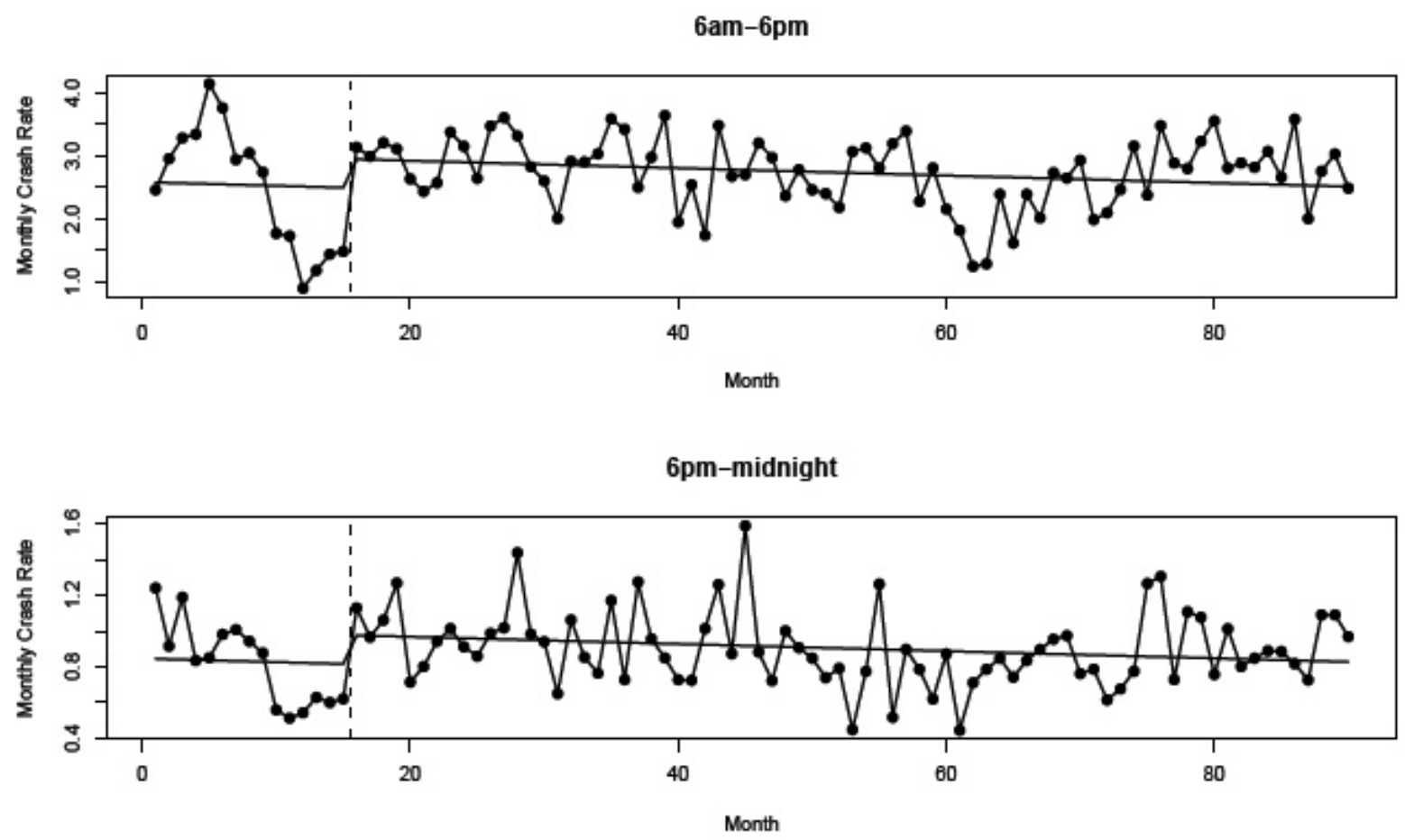

Figure 5. Adjusted monthly daytime and nighttime crash rates, Jefferson County, KY. 


\section{Discussion}

Simple comparisons of crash counts are not an appropriate method of determining the effect of a change in school start times, for a variety of reasons. They may target the wrong driver population, or ignore trends in population or other demographic variables. Simple comparisons can also confound the effect of a change in school start time with effects that could have resulted from changes in driver licensing regulations or economic conditions, both of which may influence crashes by increasing or decreasing the amount of driving. In the present study, to avoid these potential confounders, we constructed the time series of crash rates among 16- and 17-year-old licensed drivers in several North Carolina and Kentucky counties. We focused only on the times when school was in session, excluding summer months. Finally, adjustments were included for the exact number of school days during each month, and for county-specific changes in the population aged 16 and 17.

Plots of the resulting crash rates show an overall decrease for the period 2000-2007, for all four counties in North Carolina, though only Forsyth County implemented a change in the school start time during this period. This simple comparison shows the risk of making an overly hasty attribution of the decrease in crash rates in Forsyth County to the change in school start time.

To separate the possible effect of shifting the school start time from the widespread downward trend in crash rates, we conducted an intricate form of time series analysis. First, the series was differenced at a lag of 10 months (one school year), to remove the effect of seasonal variation and long-term trend. Then a regression analysis was conducted to study the specific effect of an intervention in August 2003, when the change in school start time was instituted in Forsyth County. This series still shows a significant autocorrelation, which is accommodated by assuming a seasonal ARIMA time series model for the residuals from the regression. The time series model was initially selected using the AIC criterion and further checked using the Ljung-Box test on the residuals. In some series, where there were apparent outliers, further analyses were conducted after adjusting these outliers. These adjustments did not significantly affect the results of the intervention analyses.

The results show an estimated decrease in crash rates of about $14 \%$ in Forsyth County at the time of the change in school start times, which is statistically significant using a 
one-sided test $(p=.038)$. However, a comparable analysis for Guilford County also showed a change of about the same percentage (though smaller in absolute value and not statistically significant). This serves as a further caution against over-interpreting the result for Forsyth County, as there may be other factors at work that produced the decrease in crash rates at around this time. However, in the other two comparison counties, there was no evidence of any shift in crash rates. Moreover, the pattern of changes across the day was different in Guilford and Forsyth Counties. This suggests that the apparent change in Guilford County reflects something unique to that county rather than a general pattern of declining crash rates among high school age drivers in urbanized regions of North Carolina.

One possible explanation for the puzzling decrease in Guilford County, but not in the other two comparison counties examined, is that a county-wide program focusing on teenage drivers was conducted from August through December, 2004 (Goodwin et al., 2006). This involved 25 law enforcement checkpoints in the vicinity of high schools as school was dismissed, focusing on compliance with young driver license restrictions (limit on passengers, requirement of belt use). There were also stepped up nighttime patrols, to address compliance with a limit on night driving by drivers with an intermediate driver license. These enforcement activities were accompanied by extensive publicity. The combination of enforcement and publicity of the enforcement has repeatedly been shown to produce changes in high risk driving (Lacey, Jones \& Smith, 1999; Reinfurt, 2004; Williams \& Wells, 2004). Moreover, the overall decline in the Guilford County crash rate was due almost exclusively to a decrease between $3 \mathrm{pm}$ and $6 \mathrm{pm}$, whereas Forsyth crashes increased sharply during this time of day. This is the time period when enforcement activities in Guilford County were most visible to high school students, with the checkpoints conducted in the vicinity of schools. The initiation of this program followed the school start intervention point by a year, so this explanation for the shift in Guilford County is quite speculative. Nonetheless, the absence of any evidence of a crash rate reduction in the other two counties considered suggests that the Forsyth County decrease is not merely the result of a general decrease in young driver crashes in urbanized North Carolina counties that happened to coincide with the shift in school start time in Forsyth County.

More detailed analyses for Forsyth County, breaking the day into three-hour periods, showed no overall change in crashes from 6 am - 9 am, a slight decrease from 9 am noon, a much more significant decrease between noon - 3 pm, and an increase in 3 pm 
$-6 \mathrm{pm}$. These results are consistent with the shift in the concentration of after-school driving from around 2:25 pm before the change to 3:40 pm after the change. Corresponding analyses for the other three counties showed no change except for the 3 pm -6 pm period in Guilford County.

Hour-by-hour analysis of crashes in Forsyth County showed statistically significant decreases in the hours following $6 \mathrm{am}, 7 \mathrm{am}, 10 \mathrm{am}$, and $2 \mathrm{pm}$, and increases in the hours following 8 am and $3 \mathrm{pm}$. Except for the 10 am decrease, which is hard to explain, these results are consistent with what would be expected given the start and finish times both before and after the intervention. We thought the rather notable decrease in crashes between 10 and 11 am in Forsyth County may have reflected a shift in the lunch hour. There is a mid-day increase in crashes among high school age drivers who are allowed to leave school during the lunch period (Stone \& Runyan, 2005). However, follow-up investigation with school officials in Forsyth County indicated that there was a county-wide closed campus policy during the lunch hour both prior to and following the change in the school start time, so the reason for this shift remains unexplained.

There is a fairly clear pattern of change during the day, with crashes shifting in time corresponding to the change in school start and finish times. However, the critical question for school board policy is whether the change in school start time has produced an overall decrease in the rate of school-age driver crashes. The analysis shows a statistically significant decrease in standard crash rates for Forsyth County associated with the change in school start time. Two of the three comparison counties Mecklenburg and Wake - showed no evidence of any change at this point of time, but there did also appear to be a shift in Guilford County, of about the same percentage change, though this was not statistically significant. This apparent change in a county that did not alter the school start time, together with the relatively modest level of statistical significance for the shift in Forsyth County, suggests caution in our overall conclusion. Nonetheless, the preponderance of evidence seems to point to a crashreducing effect of this policy change.

There is little evidence that the reduction in crashes resulted from reductions in driver sleepiness. If this were the case, crashes early in the early morning and late in the evening would have been most likely to decline with the later start time. The decrease from 7-8 am was largely, though perhaps not entirely, offset by an increase from 8-9 
am, suggesting a shift due to altered time of exposure rather than a decline that would be expected from decreased drowsiness of drivers on the trip to school. There were too few crashes at night to detect any pattern.

Other studies have reported that a later start time does reduce sleepiness among high school students, but the effect of this on crashes may simply be too small to detect in a population of the size studied, given the many other factors that influence crashes. Moreover, not all 16- and 17-year-old drivers in Forsyth County would have been influenced by the public high school start time. Some were private school students; others would have dropped out of school entirely. Finally, it may be that the shift in school start time decreased after-school driving by compressing the after-school part of the day, thereby simply reducing exposure. Such an effect of the policy is no less important, even if the mechanism - reduced exposure - was different from the one originally hypothesized (fewer sleepy high school age drivers).

Re-analysis of crash data for Fayette County, Kentucky, showed no overall shift in crash rates. There were some changes in the daily pattern consistent with what would be expected based on the resulting shift in times when high school age drivers would be on the roads driving to, and after, school. The fact that we found no effect comparable to that reported by Danner \& Phillips (2008) may result from several differences in analytic approach. We included 16- and 17-year-olds only, whereas they examined crashes for 17- and 18-year-olds. We looked only at crashes on days when school was in session, whereas they considered crashes on weekends and during the summer, resulting in a less sensitive examination of potential effects of school start time.

Another possible reason for differences in the present findings from those reported earlier involves data limitations. Interpretation of the Kentucky results in the present study was complicated by the fact that the change in school start times occurred so long ago that it was only possible to obtain crash and school schedule information for a relatively brief period prior to the change. Moreover, the lack of suitable comparison counties further reduced our ability to figure out out what may have happened with young driver crash rates in Kentucky more generally at the time when Fayette County changed its school start time. The young driver licensing system in Kentucky was undergoing significant changes during the same era when Fayette County changed the school start time, increasing the necessity of a comparison group to help understand the observed crash trends. 


\section{Conclusions}

It appears that the 75 minute shift in school start times in Forsyth County NC may have produced a small overall decrease in crashes among 16-17-year-old drivers, but the results are not definitive. The decrease in crash rates coincident with the altered start time was clear, but was only marginally statistically significant. On the other hand, the fact that no similar change was observed in the other large urbanized counties suggests this change was unique to Forsyth County. Two counties showed no decrease, another showed a non-significant, and different form of, decline. In addition to the overall decline, it is clear that the timing of Forsyth County crashes shifted, matching the later times when high school students would be driving to and from school. The lack of any notable decrease in crashes during the nighttime hours, nor any overall decrease during the early morning when students would be driving to school, suggests either that the decline in crashes was not the result of reduced sleepiness or that such an effect was too weak to detect.

A comparable analysis for Fayette County, Kentucky that focused more specifically on the population that this shift would have affected, and which controlled for other factors using a more powerful analytic approach, did not produce any evidence of a statistically significant change in crashes among high school age drivers. However, it was more difficult to detect a possible effect in Kentucky. A smaller population of 16- and 17-yearolds was potentially affected, we had limited ability to estimate the crash rates before the change in the school start time, and there were no suitable comparison counties for the analysis.

Additional studies of crashes in other jurisdictions that have altered their start times, and where the teenage driving population is sufficiently large to provide the needed statistical power to detect an effect, would be highly useful in bringing clarity to this issue. 


\section{REFERENCES}

Agent, K., Steenbergen, L. C., Pigman, J., et al. (2001). Impact of the partial graduated drivers license program in Kentucky on teen motor vehicle crashes. Transportation Research Record: Journal of the Transportation Research Board, Volume 1779 / 2001, 54-60.

Akaike, H. (1973). Information theory and an extension of the maximum likelihood principle. In 2nd International Symposium on Information Theory, ed. B.N. Petrov and F. Csaki, pp. 267-281. Budapest: Akademia Kiado.

Akaike, H. (1978) A Bayesian analysis of the minimum AIC procedure. Annals of the Institute of Statistical Mathematics, 30, 9-14.

Box, G. E. P. \& Tiao, G. C. (1975). Intervention analysis with applications to economic and environmental problems. Journal of the American Statistical Association 70, 7079.

Brockwell, P. J. \& Davis, R. A. (2003). Introduction to Time Series and Forecasting. Second edition: Springer.

Cunningham, C. M., Hummer, J. E., Moon, J.-P. (2008). Analysis of Automated Speed Enforcement Cameras in Charlotte, North Carolina (DOI10.3141/2078-17). Transportation Research Record: Journal of the Transportation Research Board, 2078/2008, 127-134.

Danner, F. W. (2002). High school start times and teen auto crashes. Sleep 25, a86a87.

Danner, F. \& Phillips, B. (2008). Adolescent sleep, school start times and teen motor vehicle crashes. Journal of Clinical Sleep Medicine, 4(6), 533-535.

Dexter, D., Bijwadia, J., Schilling, D., Applebaugh, G. (2003). Sleep, sleepiness and school start times: A preliminary study. Wisconsin Medical Journal, 102, 44-46.

Faletti, M. G., Maru, P., Collie, A., Darbey, D. G., McStephen, M. (2003). Qualitative similarities in cognitive impairment associated with $24 \mathrm{~h}$ of sustained wakefulness and a blood alcohol concentration of $0.05 \%$. Journal of Sleep Research. 12, 265274.

Foss, R. D., Feaganes, J. R., Rodgman, E. A. (2001). Initial effect of graduated driver licensing on 16-year-old driver crashes in North Carolina. Journal of the American Medical Association, 286, 1588-1592.

Goodwin, A. H., Wells, J. K., Foss, R. D., Williams, A. F. (2006). Encouraging compliance with graduated driver licensing restrictions. Journal of Safety Research, 37(4):343-351.

Hauer, E. (1997). Observational Before-After Studies in Road Safety. Pergamon, Oxford, United Kingdom. 
Hurvich, C. M. and Tsai, C. L. (1989). Regression and time series model selection in small samples. Biometrika 76, 297-307.

Lacey, J. H., Jones, R. K., Smith, R. G. (1999). Evaluation of checkpoint Tennessee: Tennessee's statewide sobriety checkpoint program [Final Report, DTNH22-94-C05064]. Washington, DC: National Highway Traffic Safety Administration..

Ljung, G. M. \& Box, G. E. P. (1978). On a measure of lack of fit in time series models. Biometrika, 65, 297-303.

National Highway Traffic Safety Administration. (2005). Drowsy driving. Annals of Emergency Medicine, 45, 433- 434.

National Sleep Foundation. (2000). Adolescent sleep needs and patterns. Washington, DC. http://www.sleepfoundation.org/sites/default/files/sleep and teens report1.pdf (accessed October 4, 2010).

Pack, A. I. et al. (1994). Characteristics of Crashes Attributed to the Driver Having Fallen Asleep. 38th Annual Proceedings of the Association for the Advancement of Automotive Medicine. Des Plaines, IL.

R Core Development Team. (2010). R: A Language and Environment for Statistical Computing. Vienna, Austria: R Foundation for Statistical Computing. (ISBN 3900051-07-0, http://www.R-project.org).

Smith, S. Horswill, M. S., Chambers, B., \& Wetton, M. (2009). Hazard perception in novice and experienced drivers: The effects of sleepiness. Accident Analysis and Prevention, 41, 729-733.

Stone, L. M., \& Runyan, C. W. (2005). High school off-campus lunch policies and adolescent motor vehicle crash risks. Journal of Adolescent Health, 36, 5-8

Vorona, R. D., Zhao, Y., Szklo-Coxe, M., Wu, A., Dubik, M., Ware, J. (2010, June). Adjacent Southeastern Cities with Dissimilar High School Start Times Manifest Different Teenage Car Crash Rates. Paper presented at the 24th Annual Meeting of the Associated Professional Sleep Societies. San Antonio, TX.

Reinfurt, D. W. (2004). Documenting the sustainability of a mature Click It or Ticket program: The North Carolina experience. Journal of Safety Research, 35(2), 181188.

Williams, A. F., \& Wells, J. K. (2004). The role of enforcement programs in increasing seat belt use. Journal of Safety Research, 35, 175-180.

Williamson, A. M. \& Feyer, A. M. (2000) Moderate sleep deprivation produces impairments in cognitive and motor performance equivalent to legally prescribed levels of alcohol intoxication. Occupational and Environmental Medicine, 57, 649655.

Wolfson. A. R. \& Carskadon, M. A. (1998). Sleep schedules and daytime functioning in adolescents. Child Development, 69, 875-887. 
Wolfson. A. R. \& Carskadon, M. A. (2003). Understanding adolescents' sleep patterns and school performance: A critical appraisal. Sleep Medicine Review, 7, 491-506.

Yang, C. K., Kim, J. K., Patel, S. R. \& Lee, J. H. (2005). Age-Related Changes in Sleep/Wake Patterns Among Korean Teenagers. Pediatrics, 115, 250-256. 

DOT HS 812221

December 2015

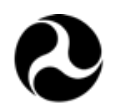

U.S. Department of Transportation

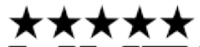
National Highway Traffic Safety Administration 